\title{
Creencias y actitudes de los jóvenes universitarios del centro-norte de España hacia las variedades cultas del español
}

\author{
Ana M. Cestero* \\ Universidad de Alcalá, España \\ Florentino Paredes ${ }^{* *}$ \\ Universidad de Alcalá, España
}

\begin{abstract}
Resumen
En este artículo se presentan los resultados sobre las creencias y actitudes que los jóvenes universitarios del centro-norte peninsular tienen en relación con las variedades cultas del español. En concreto, se analizan la creencia sobre la existencia de un modelo de español y la percepción y actitudes hacia el dialecto propio y hacia el resto de dialectos. La muestra seleccionada se compone de 204 sujetos informantes, a los que se ha aplicado la encuesta prevista en la metodología del proyecto PRECAVES XXI. Entre los resultados obtenidos, destaca que los universitarios españoles del área centroseptentrional a) valoran positivamente todas las variedades analizadas, especialmente en el componente afectivo; b) en la valoración directa,
\end{abstract}

\footnotetext{
Para correspondencia, dirigirse a: Ana M. Cestero (anam.cestero@uah.es), Universidad de Alcalá, España. Colegio San José de Caracciolos C/ Trinidad 5, 28801 -Alcalá de Henares (Madrid - España). Teléfono: +34 918854422.

** Para correspondencia, dirigirse a: Florentino Paredes (florentino.paredes@uah.es), Universidad de Alcalá. Colegio San José de Caracciolos C/ Trinidad 5, 28801 - Alcalá de Henares (Madrid - España). Teléfono: +34 918854481.
} 
reconocen y valoran más la variedad rioplatense, aparte de la propia, mientras que en el extremo contrario se sitúan las variedades chilena y andina; y c) mantienen mayoritariamente la creencia de que existe un modelo de español, que se sitúa en el español hablado en el área central o septentrional de España.

Palabras clave: creencias lingüísticas, actitudes lingüísticas, percepciones, variedades del español, castellano, PRECAVES XXI.

\title{
BELIEFS AND ATTITUDES OF YOUNG UNIVERSITY STUDENTS FROM THE CENTRE AND NORTH OF SPAIN TOWARDS EDUCATED VARIETIES OF SPANISH
}

\begin{abstract}
This article presents the results regarding the beliefs and attitudes of young university students from the centre and north of Spain towards educated varieties of Spanish. To be more precise, what is analysed here are beliefs about the existence of a Spanish standard and how one's own and other dialects are perceived and reacted to. The selected sample consisted of 204 informants who had undergone the survey prescribed in the PRECAVES XXI project's methodology. Among the results obtained, the most outstanding were that young university students from the centre and north of Spain a) regarded all varieties analysed positively, particularly their affective component; b) when evaluating directly, apart from their own, they recognised and valued highest the "rioplatense" variety of Spanish and lowest the Chilean and Andean varieties; and c) a majority believe that a Spanish standard exists as spoken in the central and northern part of Spain.
\end{abstract}

Keywords: linguistic beliefs, linguistic attitudes, perceptions, varieties of Spanish, Castilian Spanish, PRECAVES XXI.

Recibido: 29/01/2018

Aceptado: 08/06/2018 


\section{INTRODUCCIÓN: CREENCIAS Y ACTITUDES DE HABLANTES DEL CENTRO DE ESPAÑA (VARIEDAD CASTELLANA)}

El estudio de las actitudes lingüísticas tiene ya cierto desarrollo y tradición; sin embargo, y a pesar de tratarse de un fenómeno con incidencia transcendental y destacada en los procesos de variación y cambio lingüísticos y, de manera particular, en el uso de variantes, variedades y lenguas, bien entrado el siglo XXI no se ha llegado al grado de profundización en su conocimiento que sería deseable. Este panorama general es plenamente trasladable al ámbito de dominio del español y, especialmente, al español de España, pues, como recuerdan Moreno y Moreno (2004: 6), no ha sido un tema de estudio priorizado en la investigación lingüística, aunque habitualmente se considere nuestro español, concretamente el del centro-norte peninsular, como la variedad más estándar e irradiadora de norma, y de contar en el país con diversas situaciones de lenguas en contacto.

España es un territorio que presenta gran variación sociolingüística. Precisamente, la peculiaridad de que varias comunidades autónomas tengan situaciones de convivencia de lenguas, muy diferentes entre sí, ha favorecido que la mayoría de los poco numerosos trabajos dedicados a conocer percepciones y actitudes lingüísticas -funcionamiento y repercusión- se centre en lo que acontece en alguna comunidad bilingüe: Cataluña y Valencia (Vallverdú 1980, Blas Arroyo 1995 y 1999, Gómez Molina 1998 y 2002, Casesnoves Ferrer 2001, Martínez y Blas 2011, Buzón, Gómez y Gómez 2017), el País Vasco y Navarra (Oroz Bretón 1988) o Galicia (Rojo Sánchez 1979 y 1981, Fernández Paz 2001, Casares et al. 2003) o en varias a la vez (Siguán 1994). Y se puede decir que son muy escasos los estudios realizados para descubrir percepciones y actitudes de los sujetos españoles hacia variedades dialectales o normativas del español, o hacia su propia variedad ${ }^{1}$.

La pretensión de la investigación que aquí se presenta es conocer cuáles son las creencias y actitudes de los hablantes que tienen una variedad

\footnotetext{
Sin pretensión de exhaustividad, se recomienda consultar los trabajos que siguen, que se ordenan por zonas objeto de estudio, desde las propias de las variedades más tradicionales del norte peninsular, hasta las innovadoras del sur: Martín Zorraquino (1998), Álvarez y de Andrés (2001), López Morales (2001), Molina Martos (1998), Moreno y Moreno (2004), Yraola (2014), Martínez y Moya (2000), Hofseth (2012), Almeida Suárez (1994) y JohansenToft (2007). Véanse, también, los estudios de Bentivoglio y Sedano (1999) y de Díaz y Navarro (2009), en los que se trabaja con sujetos españoles y de otros países de habla hispana.
} 
castellana, del centro-norte peninsular, hacia las variedades cultas del español y, especialmente, hacia su propia variedad, con el fin de llenar un poco más el vacío de conocimiento existente sobre el tema. Se trata de un trabajo enmarcado en el Proyecto para el estudio de creencias y actitudes hacia las variedades del español en el siglo XXI (PRECAVES XXI), que utiliza técnicas de recogida de datos directas e indirectas para documentar valoraciones de los sujetos (desde dimensión cognoscitiva y desde dimensión afectiva) que den cuenta de sus percepciones y actitudes. Se pueden considerar precedentes los trabajos de Molina Martos (1998), Moreno y Moreno (2004) e Yraola (2014), en los que se trabaja también con sujetos que tienen la variedad castellana o centro-norteña para conocer actitudes hacia sus propias variedades u otras variedades del español, y que nos permiten ofrecer datos complementarios de gran interés.

Molina Martos (1998: 60-71), en una investigación realizada a principios de los noventa del siglo XX sobre las encuestas sociolingüísticas de Toledo del Atlas Lingüístico y Etnográfico de Castilla La Mancha (García y Moreno 1987), analiza creencias y actitudes de los toledanos a partir de sus respuestas a cinco preguntas, a saber: ¿qué lengua habla?, ¿cómo llaman a los de Toledo?, ¿cómo se habla en Toledo?, ¿dónde se habla mejor que en Toledo? y ¿qué cosas se dicen en Toledo peor o mejor que en otros sitios? La autora concluye que los toledanos consideran, mayoritariamente, que hablan castellano, que los llaman "bolos", que en Toledo se habla bien o sin rasgos positivos ni negativos, que en la zona central y norteña es donde mejor se habla y que en Toledo hay sobre todo rasgos fónicos no bien considerados (el yeísmo, el debilitamiento o pérdida de /d/ intervocálica y de/s/ implosiva, entre otros). Los resultados obtenidos permiten considerar, pues, a Molina que las creencias positivas o neutras prevalecen sobre las negativas (que, además, son características de las personas mayores) y, por tanto, la identidad del toledano no está en conflicto con la variedad que usa (Molina Martos 1998: 68-69).

En el trabajo de Molina se ofrecen ya datos sobre la percepción de castellanos hacia su propia variedad, y hacia otras. Aunque aún son escasos, apuntan claramente la existencia de valoraciones positivas hacia la variedad castellana y, más aún, hacia la de zonas del centro-norte y madrileña, por tradición las primeras y por importancia la segunda. El prestigio de Madrid, irradiadora de norma, es, sin duda, reconocido por los castellanos, y también, como se ve en los trabajos de Moreno y Moreno (2004) y de Yraola (2014), así como en el presente, por los propios madrileños.

Moreno y Moreno exponen en su trabajo interesantes hallazgos con respecto a la percepción que tienen los hablantes madrileños de la situación lingüística de España; en concreto, dan cuenta de las percepciones de los 
madrileños sobre las diversas lenguas de España, sobre las variedades geolectales del español del país y sobre la propia habla de Madrid, así como de la incidencia en ellas de factores sociales (2004: 7). Según los autores, los resultados obtenidos en los análisis realizados permiten considerar que los hablantes madrileños, en general, diferencian claramente las comunidades bilingües de España y las perciben como distantes a la de Madrid (2004: 30); también perciben como "un poco diferentes", por un lado, las comunidades meridionales y las Islas Canarias y, por otro, la comunidad de Aragón; ocupan una posición intermedia en la graduación Asturias, Cantabria y La Rioja, y son consideradas muy próximas las comunidades de Castilla-León y, especialmente, Castilla-La Mancha (2004: 30-31). Las características sociales de los hablantes parecen funcionar como variables explicativas de los hechos encontrados y, con base en los resultados, los investigadores proponen, como hipótesis de trabajo para futuras investigaciones, "la existencia de dos tipos, arquetipos o prototipos de percepciones de las diferencias lingüísticas en España" (2004: 33): el primero, predominante entre los hombres, hablantes de un grupo intermedio de edad y con estudios universitarios, cuya percepción parece demostrar una mayor sensibilidad hacia las diferencias entre lenguas, y el segundo, predominante entre mujeres y jóvenes, que parecen dar cuenta de una percepción que demuestra mayor sensibilidad hacia las diferencias entre variedades geolectales (Moreno y Moreno 2004: 33).

Aún resultan más relevantes para nuestra investigación las consideraciones sobre la percepción que tienen los madrileños de su propia comunidad, que apuntan la existencia, también, de varios grupos sociales e, incluso, un posible cambio de actitud generacional: "los mayores parecen ver Madrid como algo distante de todo lo demás, probablemente por asumir una idea de Madrid como modelo prestigioso o por tener una idea casticista de la capital (...); los jóvenes, sin embargo, perciben Madrid como una comunidad que lingüísticamente comparte muchos elementos con la mayoría de los territorios peninsulares" (Moreno y Moreno 2004: 34).

Recientemente se publicaron los primeros resultados del Proyecto Identidad y actitudes lingüisticas en Hispanoamérica, conocido como LIAS por sus siglas en inglés, Linguistic Identity and Attitudes in Spanish-speaking Latin America (Chiquito y Quesada 2014). Enmarcado en el mismo, los análisis realizados por Yraola (2014), centrados en las actitudes lingüísticas de los madrileños, dan cuenta del conocimiento que tienen los sujetos de Madrid de su propia variedad, así como de las percepciones, apreciaciones y actitudes que muestran hacia ella y hacia las demás variedades geolectales, tanto nacionales como de fuera del país, desde las perspectivas "cognitiva, afectiva y conductual" (2014: 554). En el trabajo, el autor ofrece datos de 
gran interés que prueban la estrecha relación existente entre las actitudes lingüísticas y la aceptabilidad social, y que nos llevan a considerarlo el precedente más inmediato de nuestra investigación. Son destacables, en atención a los que en este trabajo se expondrán, los siguientes resultados presentados por Yraola: los madrileños consideran que donde mejor se habla castellano es en Madrid y en Castilla (y también son estas las variedades que más les gustan, aunque hay una muestra pequeña que apunta a Andalucía) (2014: 580-584) y la dimensión lingüística en la que se apoya tal creencia y valoración es fónica, concretamente la pronunciación o el acento; en contrapartida, la andaluza y la de Cataluña son las variedades menos apreciadas (2014: 590); la mayoría de madrileños encuestados considera que es en España donde se habla más correctamente, seguida, muy de lejos, de Colombia, Argentina y Chile, y, señala, aunque en baja proporción, España, Cuba, México y Argentina como los lugares en los que peor se habla (2014: 601-605); la riqueza del idioma, así como la identidad y la identificación cultural, son las razones esgrimidas por los madrileños al mostrar sus preferencias por la diversidad lingüística, por la variación del español (2014: 611); ahora bien, si hubiera unidad lingüística, preferirían, en una gran mayoría, el español de España (2014: 613); por último, las variedades de otros países consideradas como más similares a la propia coinciden con las preferidas, pues son Colombia y Argentina, y las más diferentes resultan, a su vez, las menos preferidas, esto es Cuba, Argentina y México (2014: 620).

Los resultados obtenidos en la investigación llevada a cabo en el seno del PRECAVES XXI permiten confirmar y completar los hallazgos de las investigaciones previas, así como configurar un marco bastante específico sobre las percepciones y las creencias y actitudes, de momento, de los jóvenes universitarios del centro peninsular hacia su propia variedad, la castellana, y hacia las demás variedades normativas del español. Se ofrecen aquí los datos más significativos y se emplaza al lector a la fase siguiente del proyecto para conocer la determinación explicativa de otros factores sociales (sexo, edad y nivel de instrucción) en los fenómenos que nos ocupan.

\section{NOTAS SOBRE METODOLOGÍA DE LA INVESTIGACIÓN: LA MUESTRA}

Como es bien sabido, la razón fundamental por la que el estudio de creencias y actitudes no ha llegado al grado de desarrollo deseado es la gran dificultad que entraña este tipo de investigación. Los métodos que han dado resultados 
más destacados utilizan técnicas indirectas, combinadas o no con directas, a partir de las propuestas pioneras de Lambert y sus colaboradores (1960). Como se ha explicado en el artículo introductorio de este monográfico, en el Proyecto para el estudio de creencias y actitudes hacia variedades del español en el siglo XXI se parte del presupuesto básico de que es posible conocer actitudes de los individuos a partir de las valoraciones que realizan, lo que nos llevó a diseñar y emplear una prueba, basada en la técnica de pares falsos o máscaras, que permite obtener, de forma directa y de forma indirecta, información sobre la valoración que los individuos hacen de las variedades cultas del español y, consecuentemente, sobre sus percepciones, creencias y actitudes hacia ellas. La pretensión es obtener datos y estudiar todo el dominio de habla hispana por zonas generales, estableciendo como tales las ocho correspondientes a las consideradas como de influencia de variedades normativas del español, a saber, centro y norte de España, sur de España, Canarias, México y Centroamérica, Caribe, Andes, Chile y Río de la Plata (Moreno Fernández 2009). Los investigadores que llevan a cabo el proyecto se ocupan de un área o subárea determinada; por lo que los autores de este artículo, con lugar de residencia y trabajo en la comunidad de Madrid, estudian las creencias y actitudes de los jóvenes universitarios del centro-norte peninsular, que tienen una variedad castellana, hacia su propia variedad y hacia las demás.

El objetivo general de la primera etapa del PRECAVES XXI, de la que se da cuenta en este monográfico, es conocer, como se ha mencionado previamente, las percepciones, creencias y actitudes de los jóvenes universitarios hacia su propia variedad y hacia las demás variedades normativas del español. Para ello, se han establecido como criterios básicos del estudio coordinado los siguientes:

- Trabajar con una muestra representativa de la comunidad o zona objeto de estudio: aproximadamente 50 sujetos por colectivo.

- Recoger datos de al menos dos colectivos diferentes: estudiantes de Filología o Lingüística sin conocimientos sobre variedades del español y estudiantes de Filología o Lingüística con conocimientos sobre variedades del español

Se trata de criterios de selección de muestra mínimos, que pueden ampliarse en atención a las peculiaridades de las distintas zonas y al estudiantado con el que se cuente. En nuestro caso, se ha podido recoger, además, muestras de estudiantes de otras carreras, sin conocimiento de la existencia de variación lingüística, y encuestas de estudiantes de máster en formación de profesores de español como lengua extranjera (ELE) que, necesariamente, deben tener conocimiento de variedades del español. 
En total, se ha trabajado con 204 informantes, todos ellos jóvenes (de entre 18 y 34 años) y universitarios (aunque algunos de ellos están en primer curso y, por tanto, se considera que su nivel de estudio es medio, pues han concluido la secundaria). Dado que en cada encuesta se valoran dos producciones con variedad castellana: una de discurso oral y otra de texto leído, contamos, en principio, con 408 respuestas hacia la variedad centro-peninsular. En las encuestas han colaborado 136 estudiantes que no han estudiado las variedades del español o la configuración lingüística de las mismas (107 estudiantes de los primeros cursos de Filología y 29 estudiantes de otras carreras) y 68 que tienen o deben tener conocimiento sobre variación geolectal (43 estudiantes de los últimos cursos de Filología y 25 estudiantes de máster de formación de profesores de español). Como son las mujeres las que muestran, tradicionalmente, preferencia por los estudios lingüísticos y filológicos, no es de extrañar que haya casi el triple de cuestionarios realizados por mujeres que por hombres. Por otro lado, se trabaja con el dominio lingüístico de la variedad castellana, lo que ha permitido recoger y analizar encuestas no solo de sujetos de Madrid, si bien son de allí la mayoría, sino también de Castilla-La Mancha y Castilla-León y, aunque únicamente por tener alguna representación, del País Vasco, de Aragón, de La Rioja y de Asturias.

La configuración de la muestra para el estudio de creencias y actitudes de jóvenes universitarios con variedad castellana queda como se recoge en la tabla 1.

\begin{tabular}{llrr}
\hline \multirow{2}{*}{ Sexo } & & & $\%$ \\
\hline \multirow{2}{*}{ Edad } & Mombres & 53 & 26,0 \\
\cline { 2 - 4 } & Mujeres & 151 & 74,0 \\
\hline \multirow{2}{*}{ Nivel de estudios } & Menores de 20 años & 61 & 29,9 \\
\cline { 2 - 4 } & De 20 a 34 años & 143 & 70,1 \\
\cline { 2 - 4 } Estudios secundarios & 47 & 23,0 \\
\cline { 2 - 4 } & Estudios universitarios & 157 & 77,0 \\
\hline & $\begin{array}{l}\text { Estudiantes de Filología sin formación } \\
\text { dialectal }\end{array}$ & 107 & 52,5 \\
\cline { 2 - 4 } & $\begin{array}{l}\text { Estudiantes de Filología con forma- } \\
\text { ción dialectal }\end{array}$ & 23 & 21,1 \\
\cline { 2 - 4 } & $\begin{array}{l}\text { Estudiantes de máster de profesores de } \\
\text { español }\end{array}$ & 25 & 12,3 \\
\cline { 2 - 4 } & Estudiantes de otras carreras & 29 & 14,2 \\
\hline
\end{tabular}




\begin{tabular}{llrr}
\hline $\begin{array}{l}\text { Comunidad de } \\
\text { origen }\end{array}$ & Madrid & 146 & 71,6 \\
\hline & Castilla-La Mancha & 40 & 19,6 \\
\hline & Castilla y León & 10 & 4,9 \\
\hline & País Vasco & 4 & 2,0 \\
\hline Aragón & 2 & 1,0 \\
\hline La Rioja & 1 & 0,5 \\
\hline TOTAL & Asturias & 1 & 0,5 \\
\hline
\end{tabular}

Tabla 1. Muestra para el estudio de creencias y actitudes de jóvenes universitarios con variedad castellana

Las preguntas de investigación a las que se trata de dar respuesta en este trabajo son las siguientes:

1) ¿Para los sujetos estudiados existe alguna variedad de español que pueda considerarse mejor o más prestigiosa?

2) ¿Qué percepción tienen los encuestados de su propia variedad, es decir, cómo la valoran?

3) ¿En qué medida los sujetos estudiados identifican el resto de variedades cultas del español y cómo las valoran?

\author{
3. CREENCIAS Y ACTITUDES DE JÓVENES \\ UNIVERSITARIOS DEL CENTRO-NORTE DE ESPAÑA \\ HACIA LAS VARIEDADES DEL ESPAÑOL
}

\title{
3.1. El PRESTIGIO DE LAS VARIEDADES
}

La primera pregunta de investigación a la que se dará respuesta tiene que ver con el estatus que se otorga a las distintas variedades del español. Las creencias y actitudes lingüísticas de un individuo están directamente vinculadas con su ideología lingüística, consistente en el conjunto de creencias acerca de la lengua, el lenguaje, las variedades lingüísticas y quienes las usan. Y es sabido que para muchos hablantes, las realizaciones 
de una lengua en diferentes áreas geográficas no son equivalentes, sino que las de unos territorios son mejores o peores que las de otras zonas, idea sobre la cual sería posible ordenar las variedades lingüísticas cualitativamente en una escala según representen el modelo ideal de lengua.

Para determinar en qué medida están asentadas estas creencias entre los madrileños, se analizan los datos correspondientes a la pregunta acerca de dónde consideran que se habla mejor el español. Los resultados sobre la existencia o no de diferencias entre variedades se recoge en el gráfico 1.

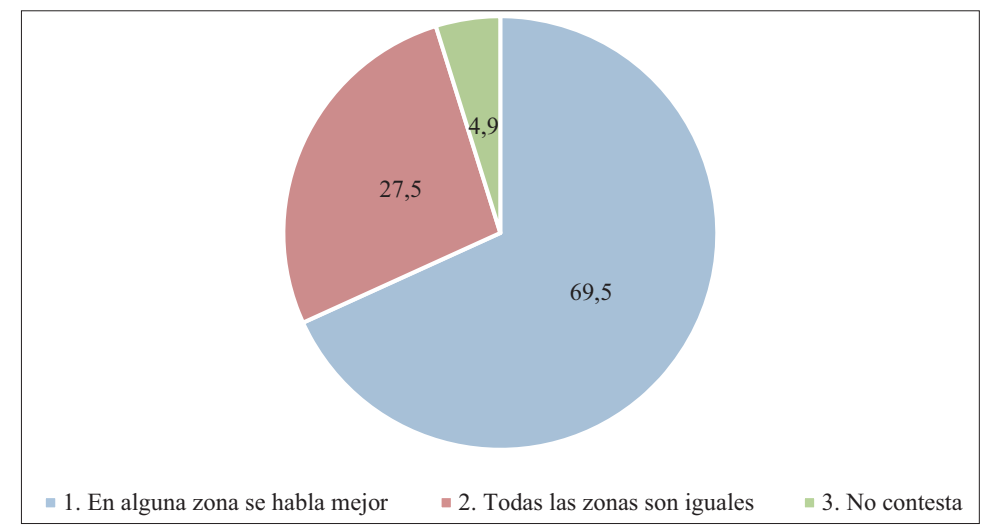

Gráfico 1. Creencias sobre la existencia de jerarquía o igualdad respecto a la existencia de región en la que se habla mejor el español

Como refleja el gráfico 1, aproximadamente uno de cada cuatro encuestados $(\mathrm{N}=56,27,5 \%)$ considera que todas las variedades del español son equivalentes ${ }^{2}$. Esta creencia aparece formulada con expresiones como las siguientes:

"En todas se habla un español igualmente bueno" (encuesta 1178)

"No existe una región o zona donde se hable mejor español" (encuesta 1009)

2 Este dato difiere notablemente del obtenido por Yraola (2014: 585), según el cual solo el 3,0\% de los sujetos responde que "todas" las regiones son equivalentes. La razón de esta divergencia puede estar en la diferente metodología que se sigue en el proyecto LIAS y en PRECAVES XXI, que afecta también a la manera en que se formula la pregunta. En el LIAS la pregunta se restringe a las variedades del propio país y por la ubicación dentro del cuestionario puede inducir al encuestado a contrastar su propia manera de hablar con la de esas otras variedades (¿En qué/cuáles tres regiones/zonas/lugares del país considera usted que hablan "mejor"?). 
"En ninguna, solo son distintas variedades de la lengua" (encuesta 1199) "En cualquier zona hispanohablante puede hablarse correctamente el español" (encuesta 1002)

Son numerosos los testimonios que, pese a reconocer la diversidad, consideran que eso no supone preeminencia de ninguna de las variedades:

"En ninguna zona se habla mejor que en otra, simplemente hay distintas variedades" (encuesta 749)

"No creo que haya una zona donde se hable mejor el español. Cada región puede tener su variedad y no por ello ser peor" (encuesta 908)

"Son dialectos diferentes, no hay mejores ni peores" (encuesta 1196)

"El español no se habla mejor o peor, sino que presenta diferentes variedades lingüísticas de gran riqueza dialectal" (encuesta 1187)

"Creo que no depende de la zona, sino de cada hablante" (encuesta 2473)

La opinión mayoritaria entre los jóvenes universitarios del centro-norte peninsular, no obstante, es que hay diferencias entre las variedades del español $(\mathrm{N}=138,69,5 \%)$, esto es, que se puede trazar una escala jerárquica en relación con un teórico modelo de buen hablar. La región inequívocamente señalada como modelo de español para los encuestados es "Castilla", respuesta que se anota a 125 de los 204 encuestados $(61,3 \%)^{3}$. La matización de que el modelo idiomático se sitúa en la variedad centro-norteña se declara con precisión a menudo:

"De la Comunidad de Madrid hacia arriba" (encuesta 1838)

"España, Madrid y alrededores" (encuesta 1815)

"En España, de Madrid hacia el norte" (encuesta 1807)

“Algunas zonas de Castilla y León” (encuesta 903)

Son escasísimas, por el contrario, las opiniones favorables a que el modelo de español se ubique en América. Solo en cuatro encuestas se manifiesta esa opinión: en dos se anota "Hispanoamérica" o "Sudamérica", en una se escribe "Venezuela" y en otra, "Colombia".

Por otra parte, el modelo de habla se ubica en las ciudades. Así se formula expresamente en varias encuestas:

\footnotetext{
3 Esta respuesta se formula de diversas maneras: "Castilla y León", se cita en 33 encuestas; el "Centro de España", en 13; "Castilla-La Mancha" en 5 y la "Comunidad de Madrid" en 4. Además, se han señalado como modelo de habla el "País Vasco" y "La Rioja", en ambos casos por un solo sujeto de cada zona. Por otra parte, ocho encuestados dieron la respuesta genérica "España", sin mayor especificación.
} 
"En las grandes ciudades españolas: Madrid, Barcelona, Bilbao, Valencia, Zaragoza y en las dos Castillas" (encuesta 1033)

“Castilla y León, en las ciudades, no en los pueblos" (encuesta 3380)

Entre las ciudades, Madrid se cita en 38 ocasiones, Valladolid en 9, Guadalajara en 4, Burgos en 3, Zaragoza en 2 y Soria, Palencia, Barcelona, Bilbao y Valencia en una. En definitiva, los resultados de este trabajo corroboran los de trabajos anteriores (Moreno y Moreno 2004, Yraola 2014) en la medida en que se sitúa el modelo de habla en la zona castellana y en las áreas urbanas.

También se ha analizado la posible incidencia de los factores sociales sobre la creencia acerca de la existencia o no de jerarquía entre las variedades del español. La prueba estadística de correlaciones muestra que sobre esta creencia solo tiene efecto el sexo del sujeto, la edad y el colectivo al que pertenece, con una significación de $p=\leq 0,05$ (Tabla 2), aunque el grado de correlación en todo caso es moderado o bajo. Ha quedado descartada la influencia de otros factores como el conocimiento de países hispanoamericanos, la profesión, la provincia o la comunidad de origen ${ }^{4}$.

\begin{tabular}{|c|c|c|c|c|c|c|c|c|}
\hline & & $\begin{array}{r}\text { Igu } \\
\text { en } \\
\text { varie }\end{array}$ & $\begin{array}{l}\text { Idad } \\
\text { tre } \\
\text { dades }\end{array}$ & $\begin{array}{r}\text { Jer } \\
\text { e } \\
\text { vari }\end{array}$ & $\begin{array}{l}\text { rquía } \\
\text { tre } \\
\text { dades }\end{array}$ & & & \\
\hline & & $\mathbf{N}$ & $\%$ & $\mathbf{N}$ & $\%$ & Total & Cramer & $\mathbf{p}$ \\
\hline \multirow[t]{4}{*}{ Colectivo } & $\begin{array}{l}\text { 4. Estudiantes de } \\
\text { otras carreras }\end{array}$ & 1 & 3,4 & 28 & 96,6 & 29 & \multirow{4}{*}{, 328} & \multirow{4}{*}{, 000} \\
\hline & $\begin{array}{l}\text { 1. Estudiantes sin } \\
\text { formación dialectal }\end{array}$ & 25 & 24,5 & 77 & 75,5 & 102 & & \\
\hline & $\begin{array}{l}\text { 2. Estudiantes con } \\
\text { formación dialectal }\end{array}$ & 19 & 47,5 & 21 & 52,5 & 40 & & \\
\hline & $\begin{array}{l}\text { 3. Profesores } \\
\text { de Español }\end{array}$ & 11 & 47,8 & 12 & 52,2 & 23 & & \\
\hline \multirow[t]{2}{*}{ Edad } & Menos de 20 años & 7 & 11,86 & 52 & 88,14 & 59 & \multirow{2}{*}{,248 } & \multirow{2}{*}{001} \\
\hline & De 20 a 34 años & 49 & 36,30 & 86 & 63,70 & 135 & & \\
\hline
\end{tabular}

4 Ha quedado descartada la influencia de otros factores como el conocimiento de otros países de habla hispana $(\mathrm{p}=0,652)$, la profesión $(\mathrm{p}=0,169)$, la provincia de nacimiento $(\mathrm{p}=$ $0,341)$ o la comunidad autónoma de origen $(\mathrm{p}=0,432)$. 


\begin{tabular}{ll|c|c|c|c|c|c|c}
\hline Sexo & $\begin{array}{l}\text { Hombre } \\
\text { Mujer }\end{array}$ & 20 & 40,0 & 30 & 60,0 & 50 & \multirow{2}{*}{248} & \multirow{2}{*}{, 001} \\
& 36 & 25,0 & 108 & 75,0 & 144 & & \\
\hline Total & & $\mathbf{5 6}$ & $\mathbf{1 3 8}$ & $\mathbf{1 9 4}$ & &
\end{tabular}

Tabla 2. Factores significativos sobre la creencia de existencia o no de modelos de mejor español

El factor más relevante sobre la creencia ha sido el grupo o colectivo al que pertenece el encuestado. Hay que recordar que este parámetro permite establecer una gradación en la formación específica de los sujetos en relación con el conocimiento de las variedades del español. Los datos muestran que la consideración acerca de la igualdad entre todas las variedades del español crece progresivamente a medida que aumenta el conocimiento y la información sobre dichas variedades. No obstante, incluso entre quienes tienen mayor formación, es muy alto el porcentaje que considera que hay regiones o áreas en las que se habla mejor el español. Por sexo, esta creencia es compartida más por los hombres que por las mujeres y, en cuanto a la edad, los más jóvenes están más convencidos de que el español de algunas zonas es mejor que el de otras, dato que podía esperarse dado que existe una correlación entre este factor y el colectivo al que pertenece (los más jóvenes son también quienes tienen menor formación dialectal).

\subsection{LA PERCEPCIÓN DE LA VARIEDAD PROPIA}

La segunda de las preguntas de investigación formuladas en esta primera fase de PRECAVES XXI (¿qué percepción tienen los sujetos estudiados de su propia variedad?) permite conocer las percepciones y actitudes de hablantes del centro-norte peninsular, jóvenes universitarios, con respecto a su variedad: la castellana.

Prácticamente los 204 informantes con los que se ha trabajado han identificado correctamente su variedad en las audiciones (bien respondiendo Centro de España, Madrid, Centro-norte peninsular, Norte de España, Castilla, Castilla-La Mancha, Castilla y León, interior de España ${ }^{5}$, o, en mucha menor medida, zonas concretas del centro-norte como Ávila, Burgos, Ciudad Real, Toledo, La Rioja, León, Navarra, Salamanca, o bien anotando 
España, dando por sentada una asociación directa entre la variedad centronorte de la Península y la propia Península $)^{6}$. Excepcionalmente, cinco informantes no identifican correctamente la variedad que oyen; todos ellos, sin embargo, la relacionan con la variedad meridional española: Andalucía, Centro-Sur de España, Córdoba, Extremadura y Murcia. Estos datos permiten afirmar, sin temor a equivocarnos, que los hablantes del centro-norte peninsular identifican correctamente su variedad ${ }^{7}$.

En relación con la identificación correcta, aproximada o errónea está, sin duda, el grado de identidad que muestran los informantes con la pronunciación; tal aspecto nos proporciona datos de gran interés, que podrían explicar valoraciones que se tratarán más adelante. A pesar de que todos los sujetos de la muestra tienen, en principio, la variedad del centronorte peninsular ${ }^{8}$, un $11,3 \%$ no considera que la variedad que ha oído, la del centro peninsular, sea idéntica o similar a la suya (el 1,0\% la considera totalmente diferente, el 6,5\% la considera ligeramente igual y el 3,8\%, bastante diferente); se trata de informantes de Alcalá de Henares (3 casos), Arganda del Rey (1 caso), Ávila (1 caso), Guadalajara (10 casos), Madrid (25 casos), Toledo (1 caso) y Valladolid (1 caso) ${ }^{9}$. No obstante, la mayoría de

6 En total, son 282 los informantes que identifican correctamente su variedad, y 110 los que la asocian de manera directa con España, lo que hay que considerar identificación aproximada, aunque quizás no sea esa la percepción o intención del informante (es posible que consideren su variedad, la centro-norte, como la española por excelencia); no obstante, estas cifras varían ligeramente, si se tiene en cuenta que un sujeto apunta como lugar de origen del hablante E, lo que parece aludir a España, y otro informante apunta España Castilla, lo que nos lleva a considerarla correcta. De esta manera, los resultados finales son: 283 identificaciones exactas y 111, aproximadas.

7 Por otro lado, hay que atender a aquellas respuestas relacionadas con la identificación de la variedad que apuntan como variedad centro-norteña alguna que no lo es. Los datos al respecto pueden relacionarse, en su mayoría, con los casos de identificación errónea de la variedad propia, pues, de las 25 ocasiones en que los informantes afirman que la variedad que oyen es la castellana -erróneamente-, 14 se corresponden con variedad andaluza y 5, con canaria, y ambas pueden ser consideradas meridionales "españolas"; los otros 6 casos de identificación errónea en este sentido podrían responder a falta de experiencia lingüística y desconocimiento de variedades del español, pues se confunde a los hablantes con personas mexicanas ( 3 casos) y chilenas ( 3 casos).

8 Han contestado esta pregunta en 397 ocasiones de las 408 correspondientes a grabaciones de hablantes de zona centro-norte peninsular. De ellas, recordemos que 5 son identificaciones erróneas de la variedad, que se eliminan para los posteriores análisis.

9 No se han encontrado diferencias significativas que permitan relacionar estos datos con el sexo de los informantes o el grupo de edad al que pertenecen. En la muestra, se trabaja con muchas más mujeres que hombres, con respecto a las respuestas sobre el tema que nos ocupa, el $73 \%$ son de mujeres y el $27 \%$, de hombres. En relación a la percepción como diferente a la propia de la variedad escuchada, los datos indican que lo consideran así el 18,1\% de los 
los informantes, concretamente el $88,7 \%$, la considera ligeramente diferente $(2,5 \%)$, bastante igual $(40,1 \%)$ o totalmente idéntica $(46,1 \%)$, ya se trate de sujetos de Madrid o la Comunidad de Madrid (Alcalá de Henares, Arganda del Rey, Cobeña, Fuenlabrada, Los Santos de la Humosa, Mejorada del Campo, Móstoles o Torrejón de Ardoz), de Castilla-León (Ávila, León, Soria, Valladolid, Zamora), de Castilla-La Mancha (Albacete, Ciudad Real, Cuenca, Guadalajara, Toledo), de Aragón (Zaragoza), de La Rioja, del País Vasco (Álava, Vizcaya) o de Asturias.

Estos datos constatan que gran parte de los sujetos de la muestra tiene conciencia geolingüística y, además, que en ello tiene especial relevancia el conocimiento de la existencia de variedades del español, pues la mayoría de las respuestas que apuntan a diferencia entre la variedad propia y la escuchada es de estudiantes de filología -o de otras carreras- sin conocimiento de variedades ( 37 de los 45 casos) ${ }^{10}$. Resulta hasta cierto punto comprensible que sean sujetos de Guadalajara (10 casos), de Toledo (1 caso), de Ávila (1 caso) o de Valladolid (2 casos) una parte de los que consideran diferente su variedad de la castellana que oyen y evalúan -por no tratarse exactamente de la misma variedad-, pero no es tan fácil de explicar el hecho de que informantes de Madrid ( 25 casos), Alcalá de Henares (3 casos) o Arganda del Rey (1 caso) consideren tener una variedad distinta a la que oyen ${ }^{11}$. En nuestra opinión, podría tratarse de pretensión de encubrir prestigio o deberse a falta de competencia geolingüística. Quizás se puedan interpretar mejor los datos después de conocer la percepción que han mostrado los informantes del centro-norte peninsular hacia su propia variedad, y que se detalla a continuación.

\subsubsection{Valoración directa de la variedad del centro-norte de España}

La valoración directa de la variedad centro-norteña de España, por parte de hablantes de esta zona peninsular, ofrece datos diversos que resultan de

hombres y el $8 \%$ de las mujeres, lo que nos permitiría hablar, de manera provisional, de mayor competencia geolectal de las mujeres.

10 Todos los informantes del colectivo Profesores de español, menos uno, consideran que la variedad escuchada -centronorteña- es totalmente idéntica o bastante igual a la suya, lo que nos permite constatar una buena formación o competencia geolingüística, necesarias para desarrollar la profesión.

${ }_{11}$ Los 5 informantes que hacen una identificación errónea de la variedad son de los siguientes lugares: 3 de Guadalajara, 1 de Ciudad Real y 1 de Madrid. Los tres de Guadalajara perciben la variedad que oyen como muy diferente a la suya, lo que podría explicar los datos, ya que considerarían que su variedad no es la castellana. 
interés. En principio, se ha documentado una valoración general positiva, ya que la media hallada en las respuestas correspondientes del cuestionario es superior a 3 (concretamente de 3,76$)^{12}$, punto intermedio de la escala de seis grados empleada, y cada media específica supera ese punto (media correspondiente a aspectos afectivos: $3,62^{13}$, y media relativa a aspectos cognitivos: $\left.3,91^{14}\right)$.

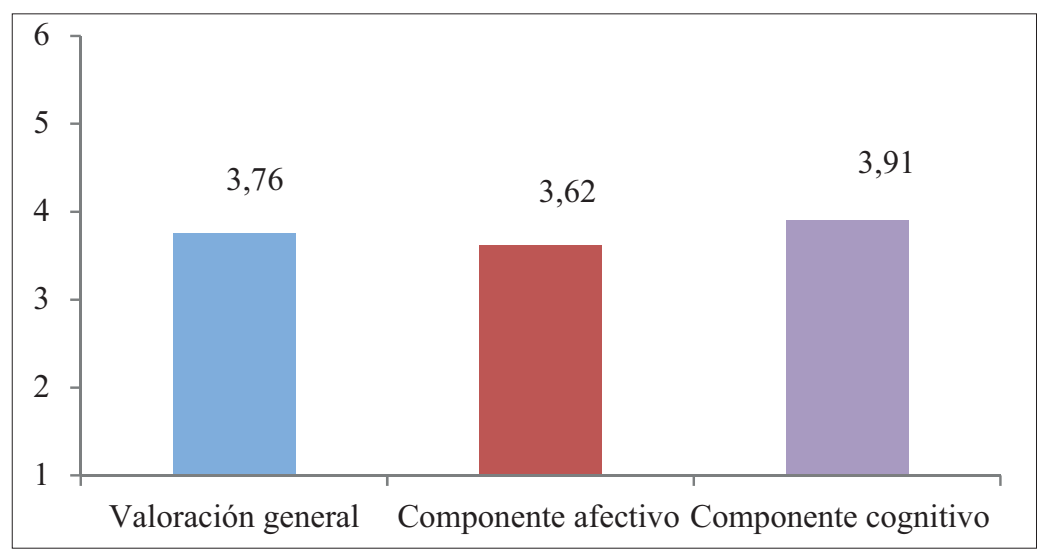

Gráfico 2. Valoración directa de la variedad castellana

Estos datos han de ser matizados y comentados con algo más de detalle, pues resulta sorprendente que la valoración de los sujetos hacia su variedad sea solo medianamente positiva, y especialmente si se tiene en cuenta que la valoración de aspectos considerados de carácter cognitivo no es mucho más alta que la de los afectivos, a pesar de que los primeros son los que se podrían relacionar de manera directa con una competencia geolingüística determinada.

12 La desviación típica es de ,63, y es significativo el hecho de que, teniendo en cuenta los percentiles, solo un 25 está en 2,8, el 50 está en 3,28 y el 75 en 3,68. La prueba de Chicuadrado ofrece los siguientes datos: sig. asintót. ,023, lo que no nos permite considerar los datos significativos, pero debe tenerse en cuenta que se trabaja con proporciones, es decir, medias, no con variantes concretas, en este caso.

13 La desviación típica es de ,85. Los percentiles son los siguientes: 25, 3,00; 50, 3,67; $75,4,17$. Ahora la sig. asintót. de la prueba Chi-cuadrado sí permite considerar los datos como significativos, pues es de, 000 .

14 La desviación típica es de ,63. Los percentiles son los siguientes: 25, 2,60; 50, 3,00; 75 , 3,40 . Como en el caso anterior, la sig. asintót. de la prueba Chi-cuadrado permite considerar los datos como significativos, ya que es de, 000 . 
Las características consideradas "afectivas" en el cuestionario con el que se trabaja presentan valoraciones diferentes por parte de los sujetos de la muestra. Así, la variedad es considerada, muy positivamente, como sencilla (media: 4,69$)^{15}$, agradable (media: 4,04), cercana (media: 3,91), bonita (media: 3,56 ) y blanda (media: 3,21 ), pero no se considera, sin embargo, divertida (media: 2,30) ${ }^{16}$. Más diversa es la valoración que hacen los informantes de la variedad a partir de aspectos "cognitivos", pues la consideran monótona (media: 5,37) y áspera (media: 4,75), pero lenta (media: 4,66), clara (media: 5,28) y urbana (media: 5,13). Estos datos parecen indicar, por tanto, que la valoración es positiva, en lo que concierne a factores afectivos y a cognitivos, lo que no impide que los hablantes reconozcan características habitualmente no consideradas positivas de su propia variedad o que, a sabiendas de tratarse de una variedad considerada prestigiosa, intenten rebajar la valoración positiva esperada.

Los aspectos valorados positivamente por hablantes del centro-norte peninsular sobre su propia variedad ${ }^{17}$ son, según ellos mismos apuntan, la claridad y la buena pronunciación, si bien también mencionan rasgos como

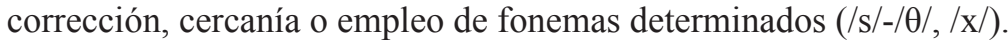

Y los aspectos de las muestras grabadas valorados negativamente por los sujetos ${ }^{18}$, de manera expresa, han sido la monotonía y la lentitud, además de la pronunciación de algunas consonantes, como las sibilantes o la /r/, y la elisión de consonantes finales.

La variable "Tipo de discurso" no ofrece diferencias importantes en las puntuaciones medias globales: oral presenta 3,74 y escrito, 3,59 ; y tampoco aparecen en las consideraciones de las características cognitivas o afectivas (discurso oral: valoraciones cognitivas, 3,93 y afectivas, 3,56; discurso escrito: valoraciones cognitivas, 3,78 , y afectivas, 3,41 ). Tampoco la variable

15 Se señalan siempre los valores que han alcanzado el nivel de significación estadística en la prueba de $\mathrm{ji}^{2}$.

16 Quizás se trate de una asociación de la característica divertida con "no seria" y los sujetos encuestados consideren que es más positiva la seriedad al hablar de una variedad lingüística.

17 Son muchos los informantes que no contestan a la cuestión que se plantea sobre aspectos de la pronunciación de la variedad escuchada - castellana- valorados positivamente. Se han recogido 106 casos de "no contesta", 210 casos de valoración positiva de rasgos fónicos, 2 casos de valoración positiva de rasgos léxicos, 5 casos de valoración positiva de rasgos pragmático-discursivos, 26 casos de otros tipos de valoraciones y 45 casos de anotaciones expresas sobre "ninguno" (hay 1 caso nulo).

18 En esta pregunta, hay 141 casos de "no contesta", 140 casos de valoración de rasgos fónicos, 23 casos de valoración de rasgos pragmático-discursivos, 33 casos de otros tipos de valoraciones negativas y 65 casos de respuestas en las que se anota "ninguno". 
"Voz evaluada" resulta incidente, pues, aunque la voz masculina obtiene una valoración media $(3,84)$ más alta que la femenina $(3,55)$, como puede apreciarse en el gráfico 3, la diferencia es poco destacable.

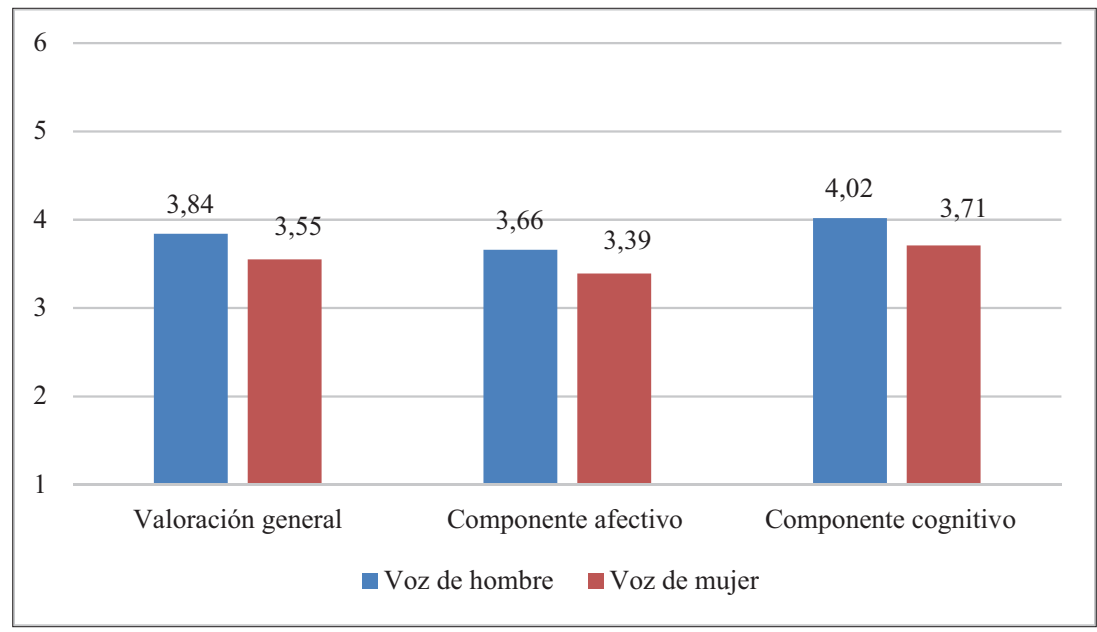

Gráfico 3. Valoración directa de la variedad castellana según la voz evaluada

Estos datos podrían asociarse al hecho de que, en la muestra, hay más mujeres que hombres (298 frente a $105-1$ caso perdido-), que encubren, de alguna manera, la valoración positiva hacia su variedad y hacia voces de personas de su mismo sexo o muestran una conciencia lingüística quizás mayor y menos subjetiva, o con una consideración más positiva del habla de los hombres, lo que resultaría contrario a los patrones sociolingüísticos constatados en la gran mayoría de los estudios realizados.

En relación con ello hay que decir que no se han encontrado diferencias sustanciales en las valoraciones medias directas de la variedad de hombres y de mujeres. Los hombres presentan una valoración media de 3,67, 3,87 en las características de base "cognitiva" y 3,47 , en las de base "afectiva". Las mujeres arrojan una media algo más baja, 3,59, 3,72 en las características "cognitivas" y 3,46 , en las afectivas. 


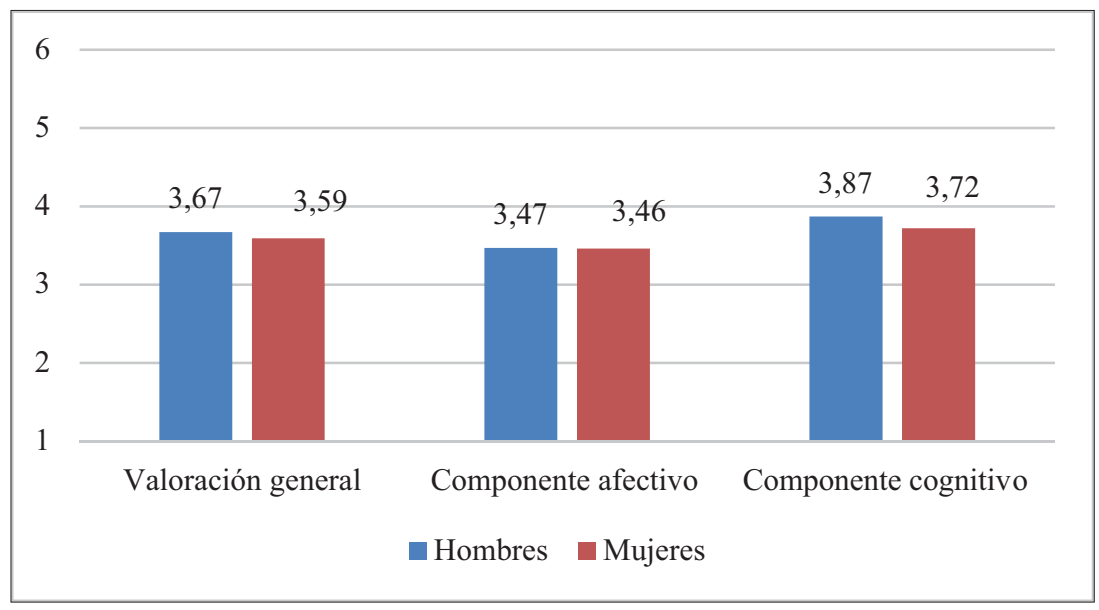

Gráfico 4. Valoración directa de la variedad castellana según el sexo

Por último, hay que considerar que, si bien no se cuenta con un número similar de informantes de los 4 colectivos, las valoraciones que han realizado los integrantes de cada uno de ellos, en promedios, resultan de interés, pues muestran el desarrollo de la competencia geolingüística con la formación específica sobre variedades del español. Los estudiantes de filología que no han estudiado variedades presentan una valoración media de 3,77 , en las características cognitivas es de 3,92 y en las afectivas, de 3,62; los estudiantes de otras carreras, que, por tanto, posiblemente tampoco tengan conocimientos específicos de variedades del español, ofrecen una valoración media de 4,08, en las características cognitivas de 4,23 y en las afectivas, de 3,93 ; los estudiantes de filología que han estudiado variedades presentan una valoración media de 3,63, en las características cognitivas es de 3,75 y en las afectivas, de 3,52, y, por último, los profesores de español ofrecen una valoración media de 3,61, en las características cognitivas es de 3,94 y en las afectivas, de 3,28. Se trata, como puede apreciarse, de diferencias muy discretas, que no parecen relevantes, pero que podría apuntar cierta relación entre conciencia y competencia geolingüística y formación específica. 


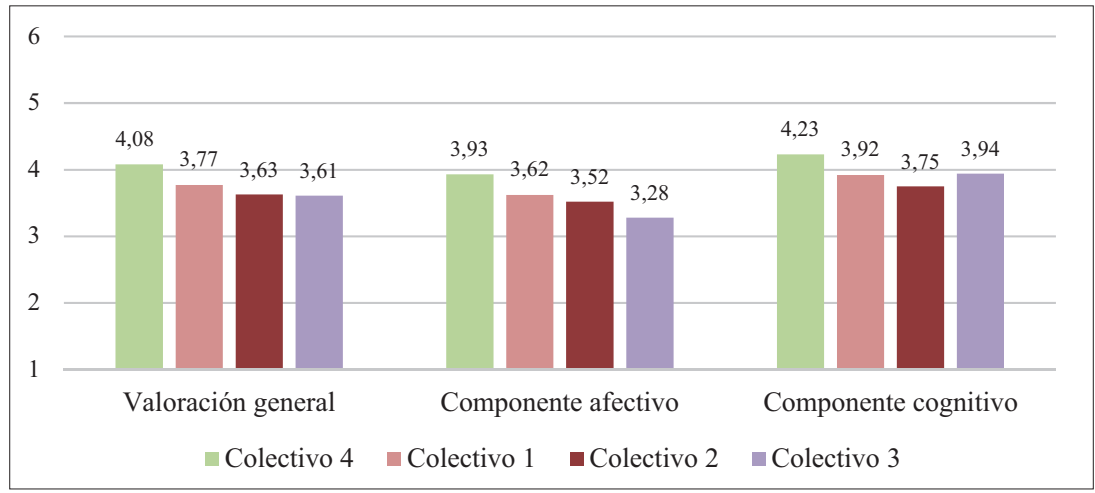

Gráfico 5. Valoración directa de la variedad centro-norte peninsular: colectivo

\subsubsection{Valoración indirecta de la variedad castellana}

Las valoraciones indirectas de la variedad del centro-norte peninsular, hacia la persona que habla y hacia la cultura de la persona que habla, obtenidas de la muestra resultan, también, de gran interés. En los párrafos que siguen se pasa a detallarlas y comentarlas.

\subsubsection{Valoración de la variedad a través de la persona que habla}

La mayoría de los informantes centro-norteños muestran creencias muy positivas respecto a su propia variedad a través de las consideraciones apuntadas sobre el puesto de trabajo (con una media de 2,40 sobre 3, de escala de poco cualificado a altamente cualificado), el nivel de ingresos (con una media de 2,38 sobre 3, de nuevo, de escala de bajo a alto) y el nivel de estudios (3,46 sobre 4, de escala de sin estudios a estudios universitarios) de los sujetos a los que han oído hablar o leer-rasgos sociales de la persona que habla-. Así, el 45,8\% de los sujetos considera que la persona que ha escuchado, madrileña, tiene un trabajo bien cualificado, y otro $45,8 \%$, altamente cualificado (un 6,4\% considera que lo tiene poco cualificado -el resto son casos de contestaciones fallidas-); el $52 \%$ cree que la persona que ha escuchado tiene ingresos medios y el $41,3 \%$, que los tiene altos (el 4,2 considera que los tiene bajos); por último, un $65,3 \%$ de los encuestados apunta que el madrileño o la madrileña que escucha tiene estudios universitarios y un $26,7 \%$, que los tiene secundarios (un $0,2 \%$ ha mencionado que se trata de una persona sin estudios y un $5,2 \%$, con estudios primarios). Las características sociales de las personas del centro-norte peninsular, por tanto, son consideradas altamente positivas. 
Es conveniente mencionar aquí que, de nuevo, es más valorada la voz masculina $(3,02)$ que la femenina $(2,50)$, ahora a partir de las características sociales de los hablantes asociadas. Se documenta 1 solo caso en el que se considera poco cualificado al sujeto, hombre, que habla (72 en que se considera bien cualificado y 144, altamente cualificado), y 25 en que se atribuye esa característica poco positiva a un sujeto cuando habla una mujer (113 en que se considera bien cualificada y 41, altamente cualificada). En relación con los ingresos, en 0 ocasiones se considera que el sujeto, hombre, que habla tiene ingresos bajos (en 87 casos se apunta que los tiene medios $\mathrm{y}$ en 128, altos) y en 17 que los tiene bajos la mujer (en 123 casos se apunta que los tiene medios y en 39, altos). Por último, en 0 casos se documenta que los informantes consideran que el sujeto que habla, hombre, no tiene estudios y en 2 que tiene estudios primarios (en 32, secundarios; en 183, universitarios), frente a 1 caso en que se considera que la mujer que habla no tiene estudios y 19 en que se indica que los tiene primarios (en 76, secundarios; en 81, universitarios).

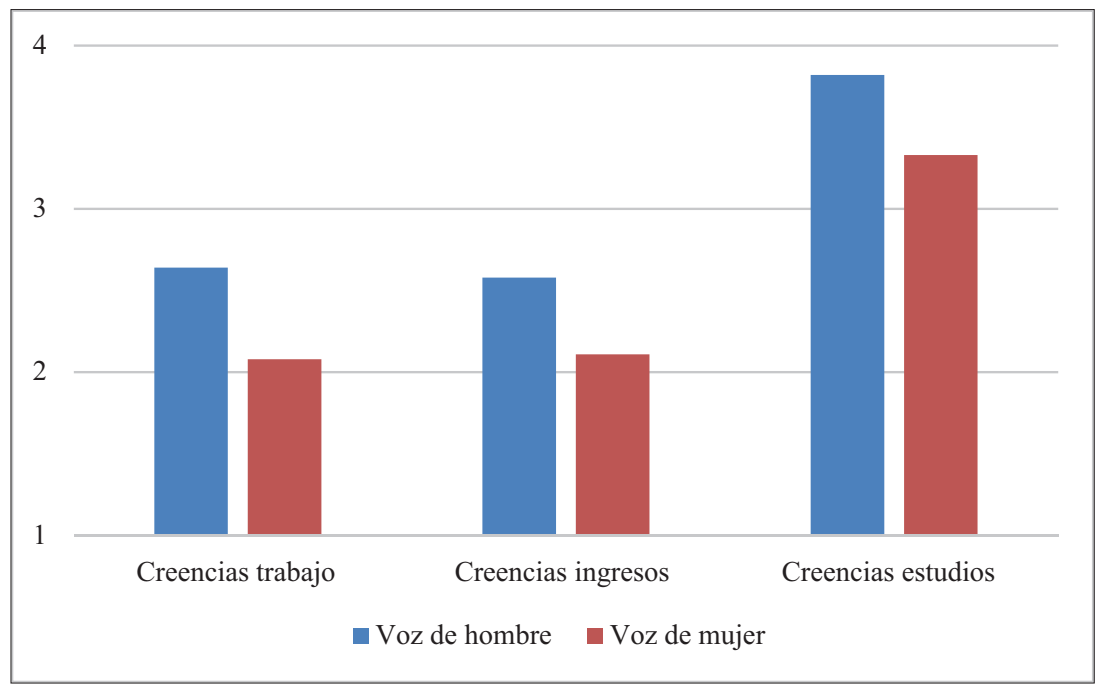

Gráfico 6. Valoración de la variedad castellana a través de las características sociológicas del locutor

No parece haber incidencia del sexo, la edad o el nivel de instrucción de los sujetos de la muestra con respecto a las valoraciones que ahora se tratan. Hombres y mujeres presentan exactamente la misma media general para los tres aspectos (trabajo, ingresos y estudios): 2,79 , si bien las mujeres suben un poco la media en lo que a estudios se refiere y la bajan ligeramente con 
respecto al trabajo y los ingresos, en comparación con las consideraciones de los hombres (hombres: trabajo, 2,40, ingresos, 2,38, y estudios, 3,59; mujeres: trabajo, 2,39, ingresos, 2,37 y estudios, 3,62).

Por último, los datos del colectivo al que pertenecen los informantes, que se relaciona con la formación específica sobre variedades, tampoco permite hablar de diferencias relevantes, aunque muestra que los sujetos que menos conocimiento específico tienen sobre variedades valoran algo más la persona y los que más conocimiento específico tienen la valoran menos. Los estudiantes de filología que no han estudiado variedades presentan una media de 2,77 (2,36 para trabajo, 3,35 para ingresos y 3,60 para estudios) y los de otras carreras, de 3,04 (2,68 para trabajo, 2,53 para ingresos y 3,89 para estudios). Los estudiantes de filología con conocimientos sobre variedades del español arrojan una media de 2,57 (2,17 para trabajo, 2,21 para ingresos y 3,35 para estudios). Los profesores de español muestran una valoración media de 2,98 (2,61 para trabajo, 2,58 para ingresos y 3,75 para estudios).

Por otro lado, las características personales de los locutores centronorteños también son valoradas muy positivamente por los sujetos de la muestra, concretamente con un promedio de 4,37 en una escala de 6 , en atención a "rasgos psicológicos y de carácter". La persona que escuchan, madrileña, es considerada, en general, muy educada (5,00 de media), muy inteligente (4,88 de media), muy culta (4,79 de media), simpática (3,59 de media) y cercana (3,58 de media).

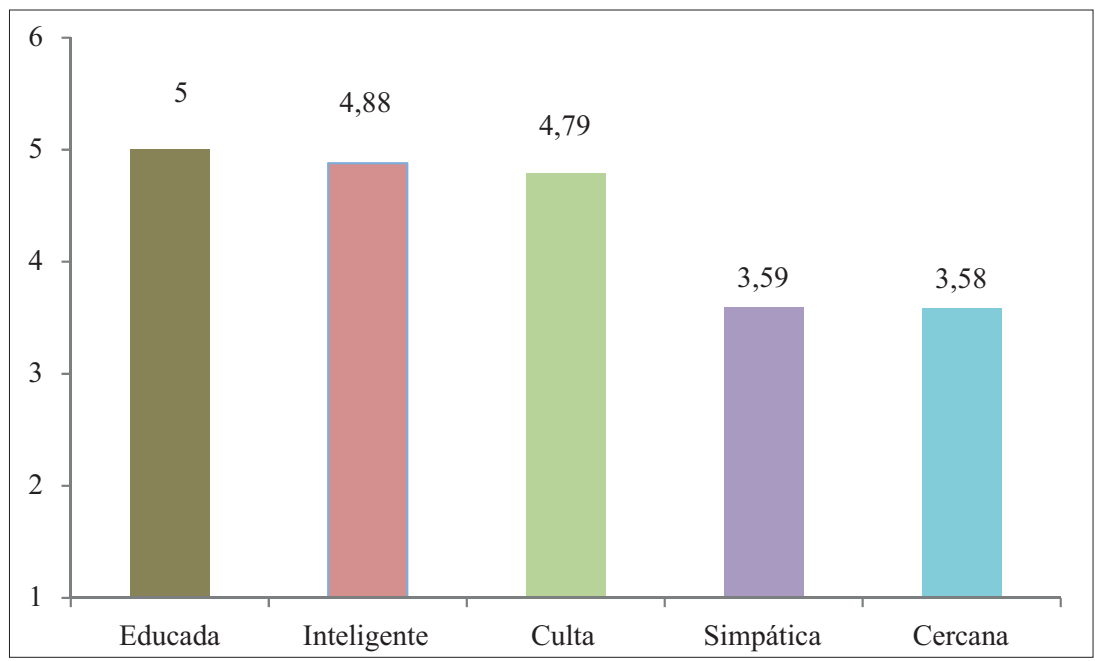

Gráfico 7. Valoración de la variedad castellana a través de las características psicológicas del locutor 
La valoración positiva de la persona que se escucha hablar, madrileña, es apuntada de manera expresa por los sujetos de nuestra muestra al responder a la pregunta que se formula para conocer su opinión sobre las personas de la región o país de los que cree que procede. Como ya comentamos, prácticamente todos los informantes reconocen que la audición con la que ahora se trabaja es de una persona del centro-norte peninsular y se identifican con ella, por eso no sorprende que el $52 \%$ de la muestra confiese tener una opinión positiva hacia las personas de la región en cuestión. De manera expresa apuntan que tienen "buena" opinión sobre las personas de la región, que se trata de gente "amable", "amigable", "agradable", "simpática", "alegre", "encantadora", "abierta", "cercana", "cosmopolita", "educada" y "culta", "activa", "buena", "seria", "sencilla", "sincera", "hospitalaria y acogedora" y "honrada".

Una vez más, resulta valorada más positivamente la voz masculina de la encuesta $(4,69$ de media) que la femenina $(3,95)$, ahora con respecto a las características personales que se mencionan. De forma más precisa, se considera que la persona que habla o lee, hombre, es muy educada $(5,34$ de media), muy inteligente $(5,25$ de media), muy culta $(5,22$ de media) y simpática ( 3,83 de media) y cercana ( 3,81 de media), y que la persona que habla o lee, mujer, es bastante educada $(4,56)$, bastante inteligente $(4,39)$, bastante culta $(4,22)$ y cercana $(3,30)$ y simpática $(3,30)$.

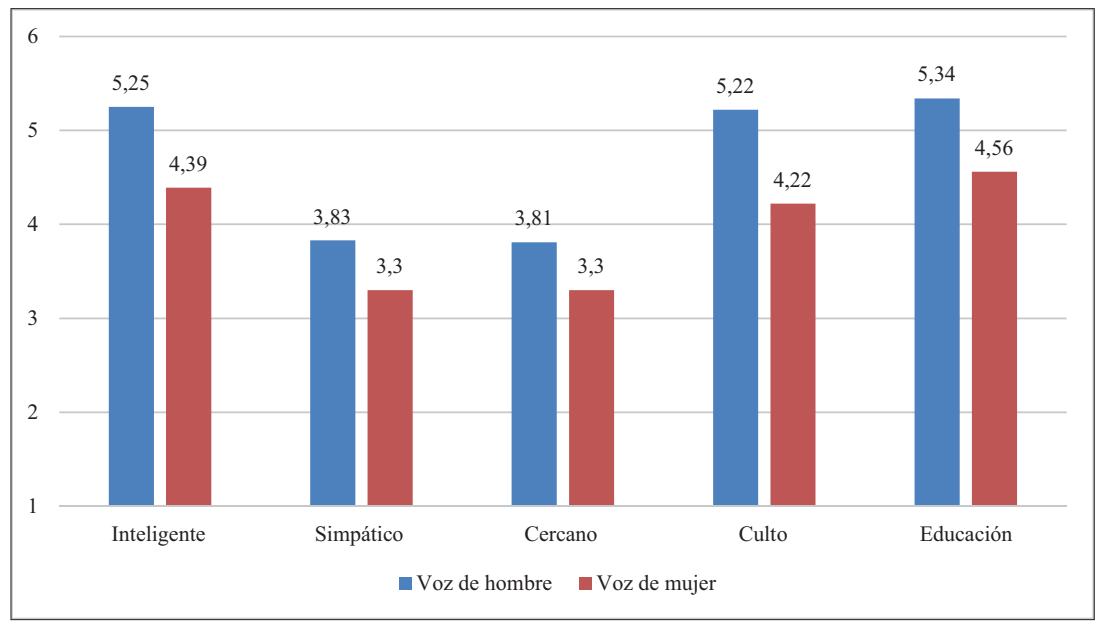

Gráfico 8. Valoración de la variedad castellana a través de características personales 
No parece haber incidencia importante del sexo, la edad o el nivel de instrucción de los sujetos de la muestra con respecto a las valoraciones sobre las personas que hablan ${ }^{19}$. Estos datos apuntan que las mujeres valoran más positivamente los rasgos personales de los centro-norteños, pero que no hay diferencias al respecto en las valoraciones de diferentes grupos de edad ni personas con distinto nivel de instrucción, posiblemente porque las diferencias etarias y de nivel, en nuestra muestra, son mínimas.

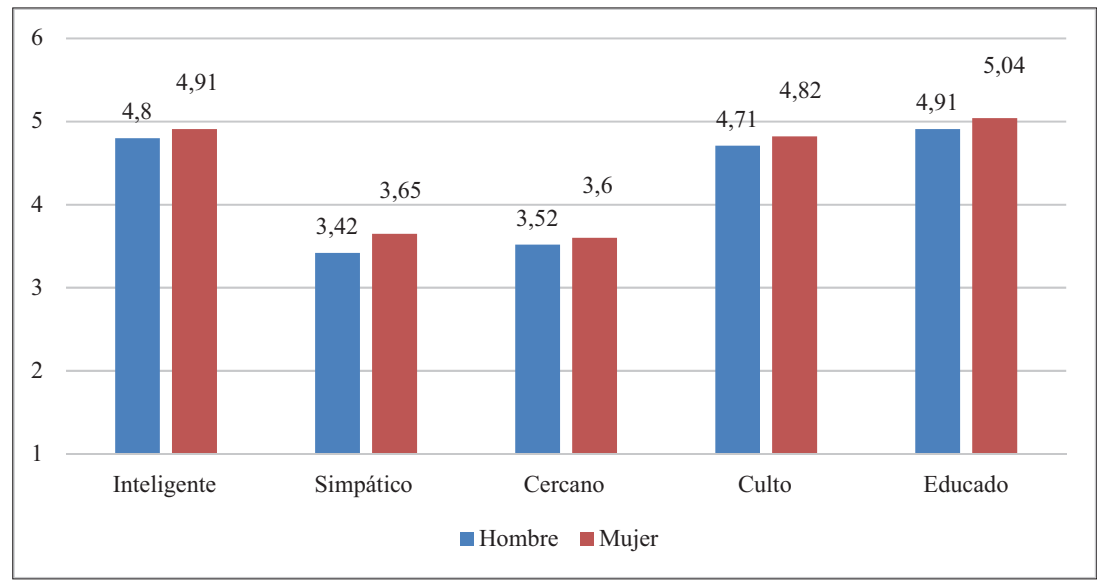

Gráfico 9. Valoración de la variedad castellana a través de características personales: sexo

No obstante, la valoración se puede relacionar con la experiencia y el desarrollo de la conciencia lingüística y sociolingüística, y con la formación específica sobre variedades del español, teniendo en cuenta, en este caso, el colectivo al que pertenece el informante. Los estudiantes de carreras diferentes a las filologías son los que presentan una valoración más positiva (4,91 de media), seguidos de los profesores de español, que no siempre son filólogos ni han tenido formación sobre variedades (4,54 de media), de los estudiantes de filología que no han estudiado variedades del español (4,33 de media) y, por último, de los estudiantes de filología que sí han tenido formación específica sobre variedades (4,54 de media).

19 Los hombres presentan una media de 4,27 sobre 6 y las mujeres algo más alta, de 4,40; los informantes del grupo etario primero arrojan una media de 4,36 , que es prácticamente la misma que la del grupo segundo: 4,37; las personas con nivel de instrucción secundaria muestran una media de 4,38 y las de instrucción universitaria, de 4,37. 


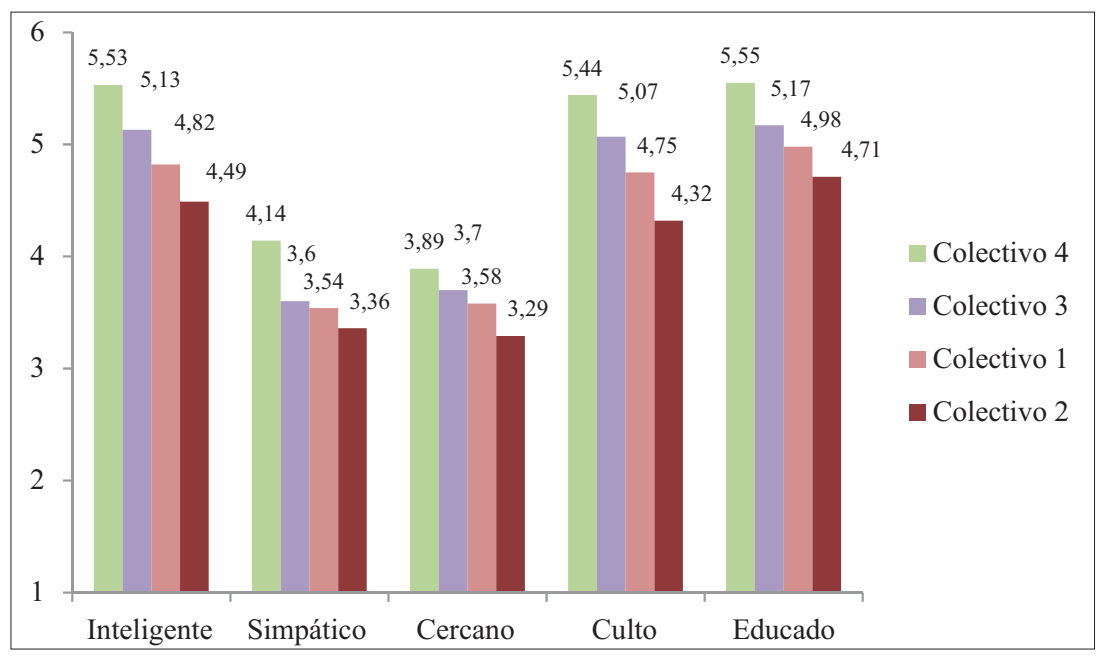

Gráfico 10. Valoración de la variedad castellana a través de características personales: colectivo

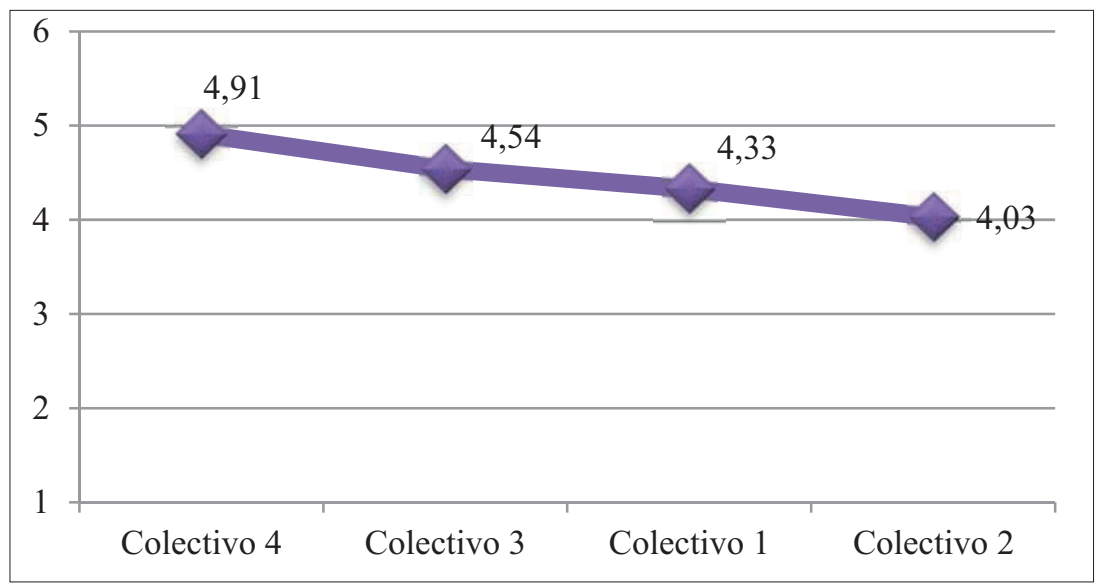

Gráfico 11. Valoración media de la variedad castellana a través de características personales: colectivo

Los datos aquí ofrecidos muestran que, por las valoraciones que han hecho sobre la persona escuchada, los sujetos del centro-norte peninsular tienen creencias muy positivas sobre su propia variedad, que, ahora sí, aunque de manera indirecta, revelan que consideran la variedad prestigiosa y modélica; tales valoraciones son algo más altas en el caso de las mujeres y más bajas, 
quizás objetivas -o atenuadas-, de los estudiantes que tienen conocimientos sobre variedades del español o especialización filológica.

3.2.2.2. Valoración de la variedad castellana a través de la región y de la cultura

Si se atiende a la valoración indirecta según la calificación otorgada a la región/país de la persona que habla y a su cultura, los resultados no difieren sustancialmente de los que se han comentado en el apartado anterior, lo que apunta creencias y actitudes muy positivas hacia la propia variedad, siendo esta la centro-norteña peninsular, considerada prestigiosa e irradiadora de norma.

La valoración de la zona o el país de la persona a la que se escucha hablar, madrileña, es altamente positiva. La media obtenida en los cuatro aspectos calificados al respecto (avanzada/retrasada, divertida/aburrida, familiar/extraña y bonito/feo) es muy alta, 4,91 sobre 6, lo que informa de una percepción bastante positiva. Tomadas por separado, todas las características apuntadas son valoradas muy positivamente, especialmente la de "bonita": la característica "bonita" tiene un promedio de 5,13, la característica "avanzada" ha obtenido una media positiva de 4,98; "familiar" ha alcanzado una media de 4,94 y "divertida" presenta una media de 4,58.

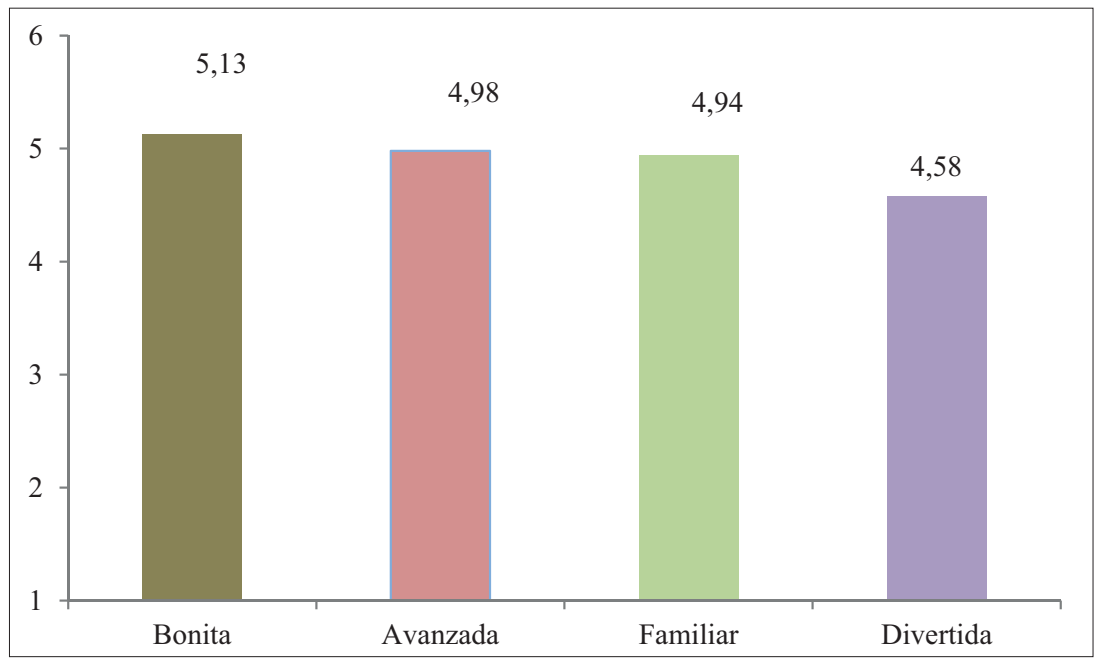

Gráfico 12. Valoración de la variedad castellana a través de la opinión que merece la zona 
En este caso, no hay una diferencia muy grande entre la calificación otorgada a partir de hablante hombre $(4,96)$ o de hablante mujer $(4,83)$. La zona de la que se cree que es el hombre que habla, centro-norte peninsular, se considera muy bonita (5,03 de media), muy avanzada (5,04 de media), muy familiar (5,00 de media) y bastante divertida (4,60 de media). Y la zona de la que se cree que es la mujer que habla, también centro-norte peninsular, se considera muy bonita (5,01 de media), bastante familiar (4,87 de media), bastante avanzada (4,87 de media) y bastante divertida (4,54 de media).

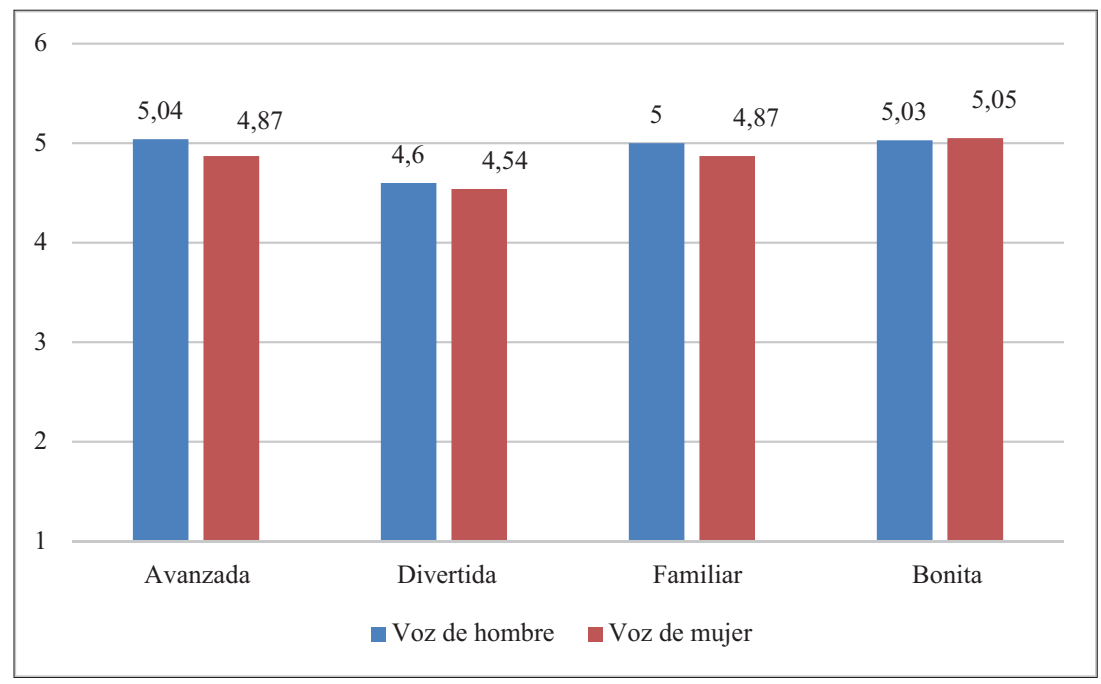

Gráfico 13. Valoración de la variedad castellana a través de la opinión que merece la zona: voz evaluada

Parece haber diferencias, en esta ocasión, entre las valoraciones sobre la zona de la que se cree que es la persona que habla realizadas por hombres $(4,68 \mathrm{de}$ media) y por mujeres (4,99 de media), de manera que las mujeres puntúan más alto que los hombres las características propuestas, especialmente la de "bonito", "avanzado" y "familiar"; no obstante, las diferencias no son tan grandes como para considerar el sexo un factor condicionante. 


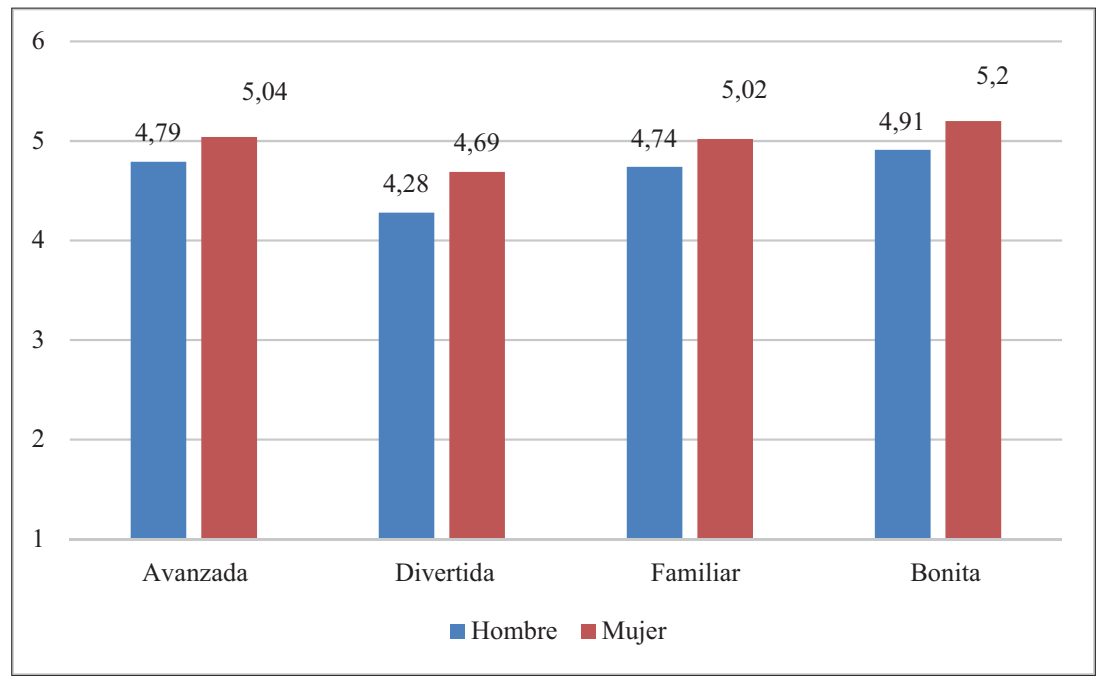

Gráfico 14. Valoración de la variedad castellana a través de la opinión que merece la zona: sexo

Por último, los datos correspondientes al colectivo al que pertenecen los informantes ofrece resultados distintos a los obtenidos hasta ahora, si bien las diferencias de proporciones no resultan tan altas como para poder considerarlo un factor determinante en la configuración de las percepciones y creencias positivas hacia la variedad centro-norteña, ahora indirectas, a través de consideraciones sobre la zona en la que se emplea. El colectivo que muestra la valoración más alta al respecto es el de profesores de español, con 5,03 de media (5,13 para avanzada, 4,81 para divertida, 4,86 para familiar y 5,34 para bonita), seguido en esta por los estudiantes que han tenido formación específica sobre variedades, con 4,92 de media $(4,89$ para avanzada, 4,71 para divertida, 4,96 para familiar y 5,10 para bonita), por estudiantes de filología que no han tenido formación específica sobre variedades, con 4,89 de media (4,98 para avanzada, 4,52 para divertida, 4,95 para familiar y 5,11 para bonita), y por estudiantes de otras carreras, sin conocimientos específicos sobre variedades, con 4,82 de media (4,95 para avanzada, 4,37 para divertida, 4,95 para familiar y 5 para bonita). 


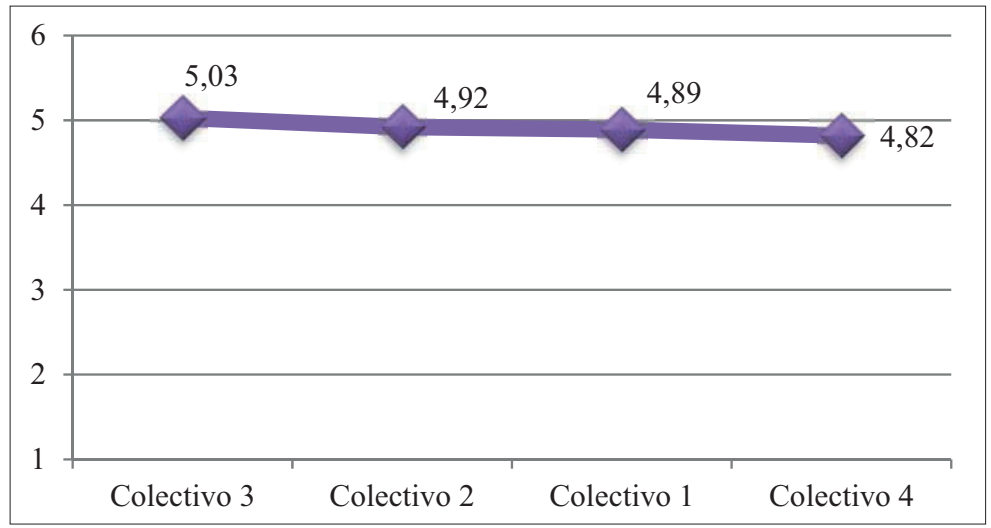

Gráfico 15. Valoración de la variedad castellana a través de la opinión que merece la zona: colectivo

Vuelve a ser muy alta la media correspondiente a la opinión de los sujetos encuestados con respecto a la cultura de su propia zona o país, $-4,80$ sobre $6-$, lo que, de nuevo, apunta valoraciones y, por tanto, creencias y actitudes muy positivas hacia la variedad propia, centro-norteña, ahora reveladas a través de consideraciones sobre la cultura. De manera general, los sujetos de la muestra apuntan que la cultura del centro-norte peninsular es "interesante" (con una media de 5,08), "cercana" (con una media de 5,01), "rica" (con una media de 4,80) e "innovadora" (con una media de 4,33).

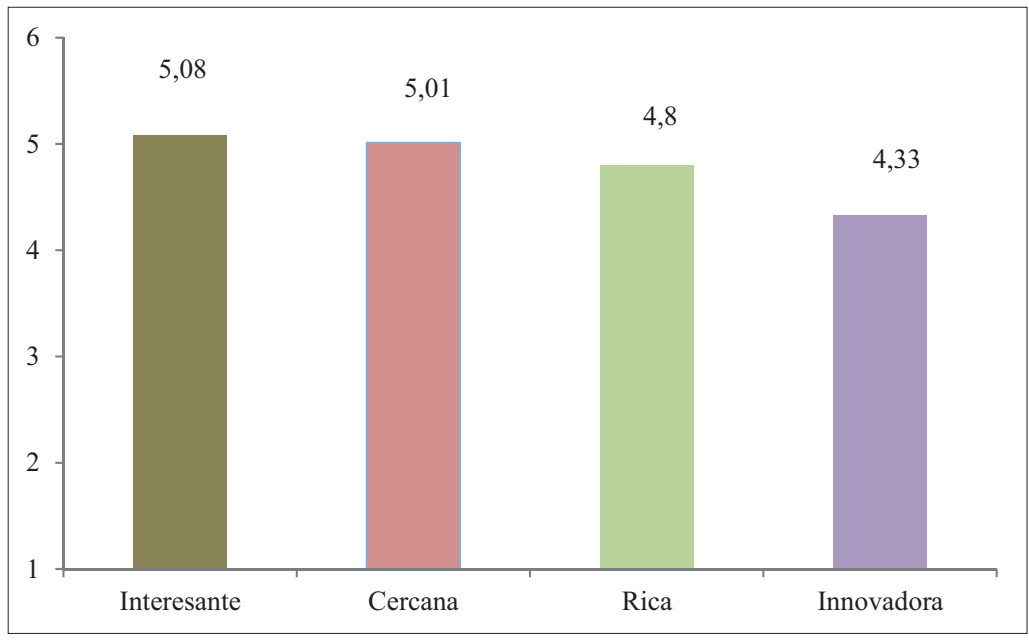

Gráfico 16. Valoración de la variedad castellana a través de la opinión que merece la cultura 
Las medias obtenidas indican que, en este grupo de características sobre la cultura, no se dan diferencias importantes en las valoraciones hacia la persona escuchada en atención a su sexo, si bien parece conveniente mencionar que las grabaciones de mujer presentan una media algo más baja, especialmente en lo que a la característica "innovadora" se refiere. Así, la media de la evaluación de voz de hombre es de 4,84 y la de voz de mujer, de 4,74; en ambos casos, se considera una cultura muy cercana y muy interesante, bastante rica y bastante innovadora.

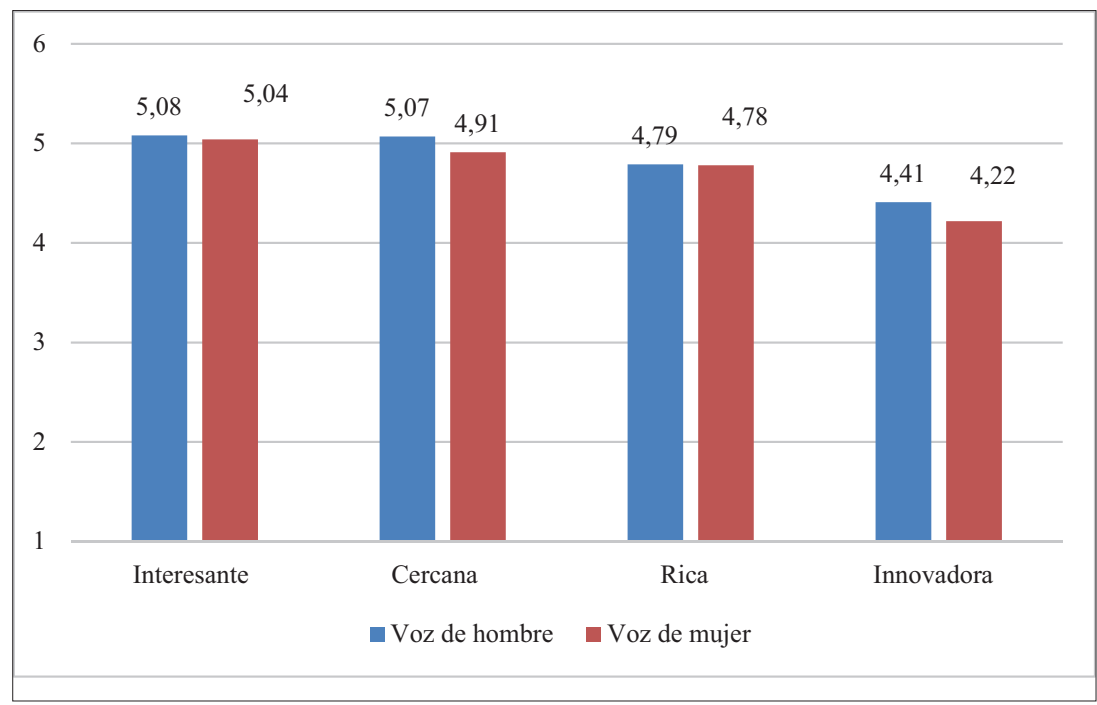

Gráfico 17. Valoración de la variedad castellana a través de la opinión que merece la cultura: voz evaluada

No hay diferencias grandes en las medias correspondientes a las valoraciones sobre este parámetro -la cultura- realizadas por hombres (4,68 de media) o por mujeres $(4,84)$, aunque parece conveniente mencionar que las puntuaciones de las mujeres son más altas en lo que respecta a los factores "cercana" e "interesante", lo que podría indicar que las mujeres valoran más características afectivas. 


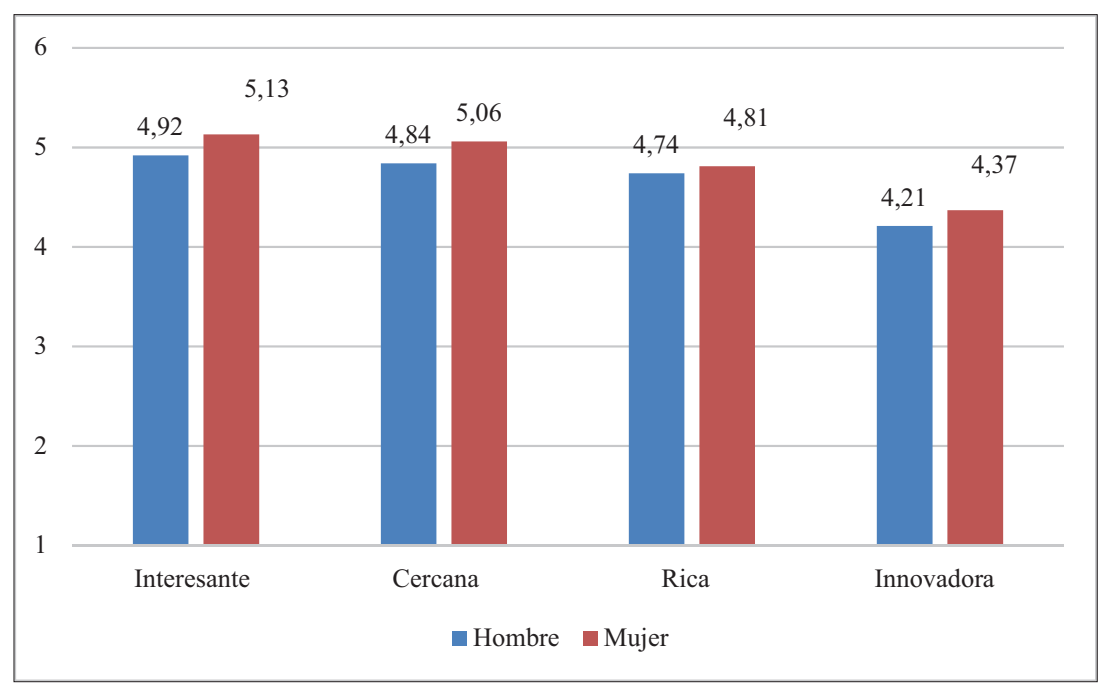

Gráfico 18. Valoración de la variedad castellana a través de la opinión que merece la cultura: sexo

Finalmente, se atenderá a los datos correspondientes al colectivo al que pertenecen los informantes, que vuelven a ser de interés, si bien las diferencias no resultan determinantes. El colectivo que muestra la valoración más alta al respecto vuelve a ser el de estudiantes de filología que no han tenido formación específica sobre variedades, con 4,84 de media $(5,09$ para interesante, 5,02 para cercana, 4,85 para rica y 4,41 para innovadora), seguido por otro colectivo sin formación específica, el de estudiantes de otras carreras, con 4,81 de media (5,18 para interesante, 5 para cercana, 4,68 para rica y 4,37 para innovadora), por estudiantes con conocimientos específicos sobre variedades del español, con 4,75 de media (5,07 para interesante, 5 para cercana, 4,77 para rica y 4,18 para innovadora) y, por último, por los profesores de español, con 4,74 de media (4,98 para interesante, 4,98 para cercana, 4,75 para rica y 4,27 para innovadora). 


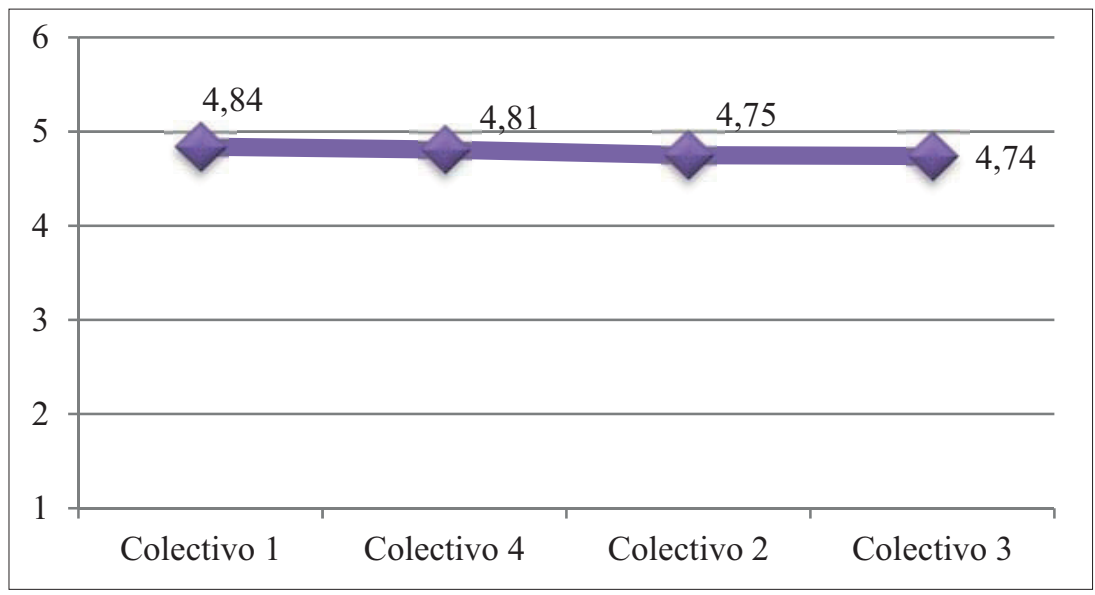

Gráfico 19. Valoración de la variedad a través de la opinión que merece la cultura: colectivo

En resumen, los datos analizados muestran la elevada consideración que los jóvenes universitarios del centro-norte de España tienen sobre la variedad propia, tanto si se considera la evaluación directa como si se atiende a la evaluación indirecta. Según los datos obtenidos, no parece haber diferencias sustanciales en relación con el sexo del evaluador, pero sí con el grado de formación específica sobre variedades dialectales.

\subsection{IDENTIFICACIÓN Y VALORACIÓN DEL RESTO DE VARIEDADES CULTAS DEL ESPAÑOL}

La tercera y última parte de este trabajo se dedica a analizar los resultados relativos a la tercera pregunta planteada en la introducción: ¿En qué medida los sujetos encuestados identifican el resto de variedades cultas del español y cómo las valoran? El objeto, evidentemente, es obtener información que permita contrastar la percepción del dialecto propio, presentado en el apartado anterior, con el resto de dialectos del español. El análisis, no obstante, no será tan detallado como en el caso anterior y se limitará a aquellos aspectos considerados especialmente relevantes.

Para empezar, se ofrecen los datos generales relativos a la identificación de variedades. Del total de 3264 audiciones que componen la muestra (recuérdese que cada informante valoró 16 audios), se consideran ahora 2856, al quedar excluidas las 408 correspondientes a la variedad castellana. 


$\begin{array}{lll}\text { Identificación exacta } & 1322 & 50,3 \% \\ \text { Identificación errónea } & 983 & 37,4 \% \\ \text { Identificación aproximada } & 322 & 12,3 \% \\ \text { No contesta } & 229 & 8,7 \% \\ \text { Total } & 2856 & 100 \%\end{array}$

Tabla 3. Identificación de variedades diferentes de la castellana por sujetos del centro-norte peninsular

Según se desprende de los datos de la tabla 3, los jóvenes universitarios del centro-norte de España identifican de manera exacta los acentos del español en uno de cada dos casos, lo que indica una capacidad elevada para identificar y discriminar dialectos. El porcentaje se amplía más si se suman las identificaciones aproximadas, que alcanzan una cota del 12,3\%. Los casos en los que los encuestados asociaron erróneamente la audición evaluada y la región suceden en menor medida $(37,4 \%)$, aunque ocurre en alta proporción pese a todo, quizá por la escasa experiencia lingüística de muchos sujetos en relación con ciertas variedades -la chilena, por ejemplo-.

\begin{tabular}{lccccc} 
& $\begin{array}{c}\text { Identific. Identific. Identific. } \\
\text { exacta }\end{array}$ & $\begin{array}{c}\text { No } \\
\text { errónea }\end{array}$ & Total \\
& 174 & 125 & 65 & 42 & 406 \\
\hline C4. Estudiantes de otras carreras & 42,9 & 30,8 & 16,0 & 10,3 & 100,0 \\
\hline & 661 & 526 & 163 & 148 & 1498 \\
\hline $\begin{array}{l}\text { C1. Estudiantes sin formación } \\
\text { dialectal }\end{array}$ & 44,1 & 35,1 & 10,9 & 9,9 & 100,0 \\
\hline & 320 & 193 & 66 & 23 & 602 \\
\hline $\begin{array}{l}\text { C2. Estudiantes con formación } \\
\text { dialectal }\end{array}$ & 53,2 & 32,1 & 11,0 & 3,8 & 100,0 \\
\hline & 167 & 139 & 28 & 16 & 350 \\
\hline C3. Profesores de Español & 47,7 & 39,7 & 8,0 & 4,6 & 100,0 \\
\hline & 1322 & 983 & 322 & 229 & 2856
\end{tabular}

Tabla 4. Grado de identificación de las variedades cultas según el grupo

En cuanto a la distribución por grupos (tabla 4), el grado de identificación exacta aumenta a medida que sube la formación dialectal, como cabía esperar, de manera que los sujetos que han recibido formación en este sentido son los únicos que superan el 50\% de los aciertos. Se constata, pues, que la 
formación explícita se convierte en un factor decisivo en la identificación y reconocimiento de las variedades dialectales del español. No obstante, llama la atención que el grupo que obtiene el porcentaje más elevado de errores en la identificación sea el de quienes estudian el máster de profesorado de ELE, a quienes a priori se les debería presuponer una mayor cualificación en este ámbito. El dato resulta especialmente relevante de cara a posibles repercusiones en el comportamiento del profesor en el aula.

Presentados los datos generales relativos al reconocimiento de las variedades dialectales cultas, se analizarán ahora los casos de identificación exacta de cada variedad. De acuerdo con la tabla 4 , estos quedan reducidos a los de las 1322 audiciones en que los evaluadores identificaron con exactitud el área de origen del locutor.

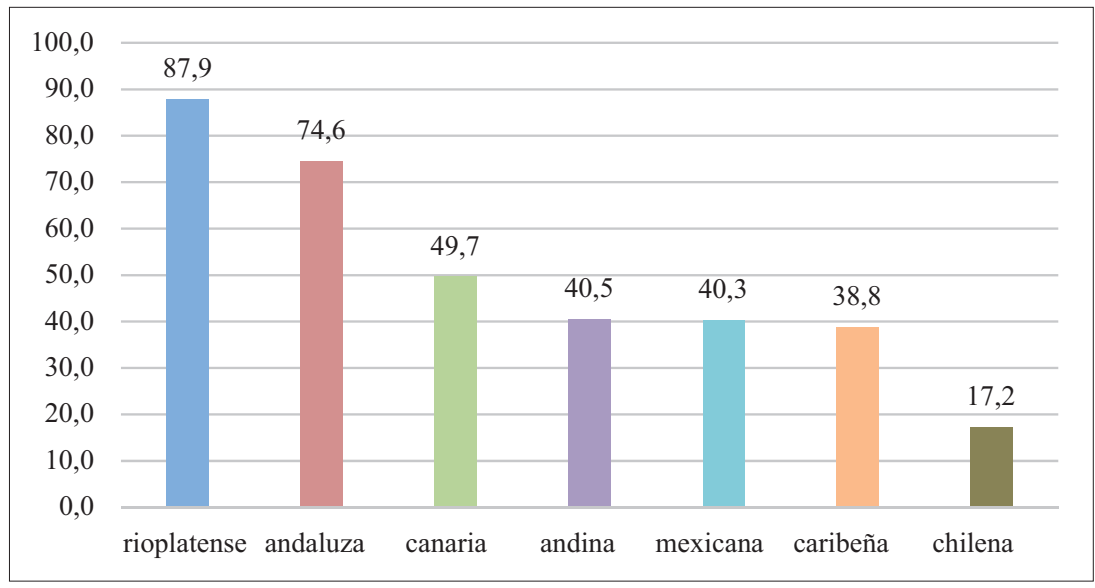

Gráfico 20. Porcentaje de identificación exacta de las variedades por universitarios jóvenes del centro-norte peninsular

La variedad más claramente reconocible por los jóvenes universitarios centro-norteños es la rioplatense, cuyo porcentaje de acierto en la identificación se sitúa en el 87,9\% (gráfico 20), por encima incluso del acierto exacto sobre la propia variedad (cf. $\S 3.2$, especialmente notas 5 y 6). También es perfectamente reconocible para los encuestados el acento andaluz, identificado con exactitud el 74,6\% de las ocasiones. En el resto de variedades el acierto en la identificación exacta está por debajo de la mitad de las veces que se oye. El dialecto canario se identifica con exactitud la mitad de las veces aproximadamente $(49,7 \%)$, y algo más baja es la proporción en que se identifican el dialecto mexicano, el caribeño y el andino; el acento menos reconocible para los jóvenes universitarios del centro-norte 
peninsular es el chileno, que solo se identifica con precisión el 17,2\% de las ocasiones en que es oído; la casusa puede estar en la falta de contacto con esta variedad americana.

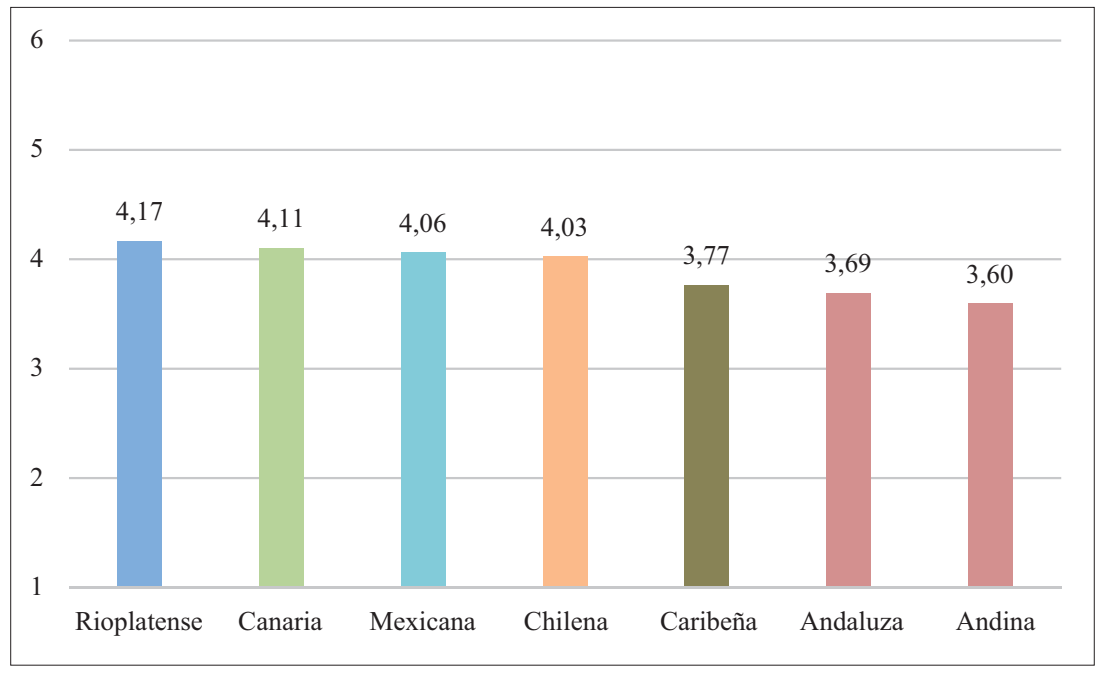

Gráfico 21. Valoración global directa de las variedades por universitarios jóvenes del centro-norte peninsular

La valoración global de las variedades cultas arroja algunos resultados que merecen comentario (gráfico 21). En primer lugar, se destaca que casi todas ellas reciben una valoración favorable, con una puntuación media por encima del 3,5, límite que separa la evaluación positiva de la negativa. En segundo lugar, que la consideración de cada una de las variedades no difiere notoriamente, como indica el hecho de que la distancia entre la más valorada y la menos apenas supere el medio punto y que el promedio de todas ellas se sitúe en 3,92. El dialecto rioplatense vuelve a situarse en primera posición, siendo por tanto el mejor valorado por los jóvenes universitarios del centro-norte peninsular. Le siguen, en orden descendente, el canario, el centro-mexicano y el chileno, y cierran la escala el caribeño, el andino y el andaluz, los únicos dialectos que no alcanzan el 4 en el promedio de la valoración directa.

Por último, los datos también permiten constatar que el grado en que es reconocible un acento no influye en la valoración que se le otorga (cf. gráfico 20). En efecto, aunque la variedad rioplatense es la más reconocible y también la más valorada, en el resto de dialectos esa situación no se mantiene. Este hecho es especialmente llamativo en el caso del andaluz, el segundo mejor reconocido y el penúltimo en cuanto a valoración. 


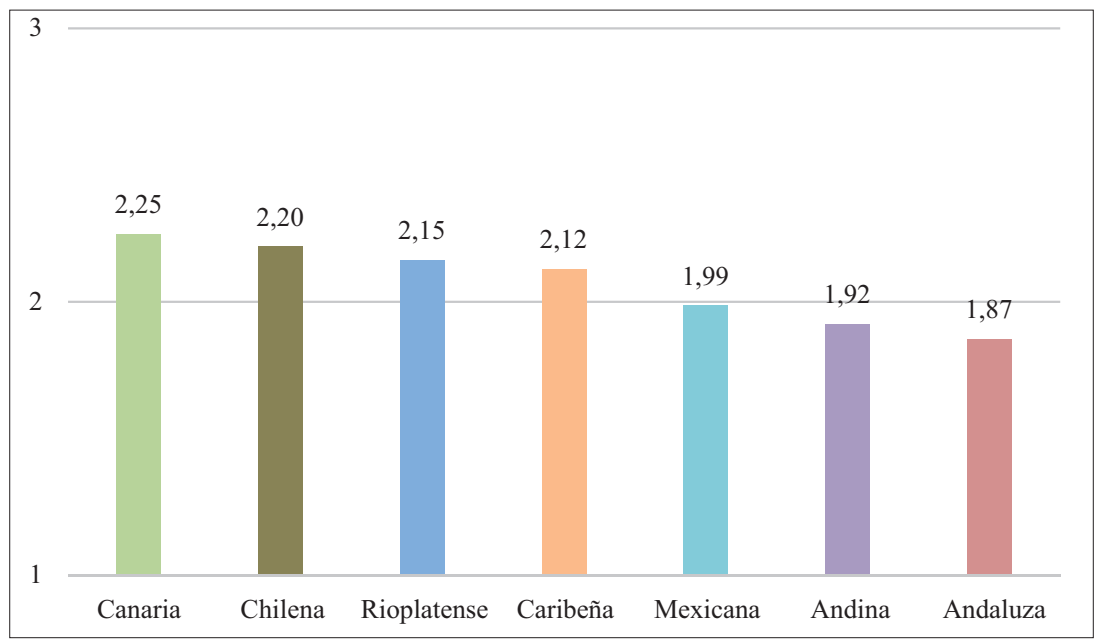

Gráfico 22. Creencias de los jóvenes universitarios del centro-norte peninsular sobre las características sociológicas atribuidas al locutor (valoración media)

La situación descrita en los párrafos anteriores cambia en cierta medida si se considera la valoración indirecta de las variedades a través de las características de la persona que habla, el país y la cultura. Centrándonos en primer lugar en la consideración de las características que los evaluadores otorgan a los locutores (que se refieren a la cualificación del trabajo, al nivel de ingresos y al nivel de estudios, como se ha explicado), los sujetos del centro-norte peninsular evalúan a los hablantes con una media alta, en todos los casos por encima del 1,8 en una escala sobre $3^{20}$, como puede observarse en el gráfico 22. En cuanto a la consideración de cada variedad, las características sociológicas más altas se atribuyen a los locutores canarios y chilenos, mientras que en extremo contrario se sitúan los andaluces y los de la región andina.

20 En la elaboración del gráfico se ha convertido a una escala de tres grados los valores relativos al nivel de estudios, que se evalúan en 4 grados, con objeto de hacerla equivalente a la del nivel de ingresos y la de la cualificación del trabajo. 


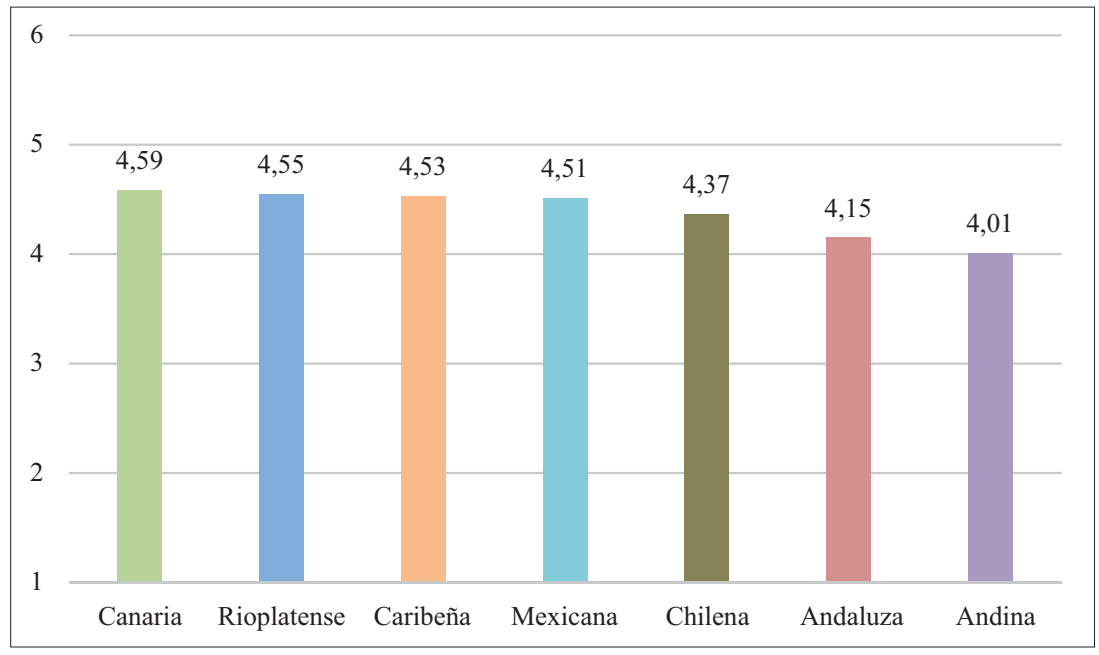

Gráfico 23. Creencias de los jóvenes universitarios del centro-norte peninsular sobre las características psicológicas atribuidas al locutor (valoración media)

En cuanto a las características psicológicas atribuidas al locutor ("inteligente", "simpático", "cercano", "culto" y "educado" o sus correspondientes antónimos), la evaluación también es muy favorable, al situarse en todos los casos en una media por encima del 4 sobre 6 y con una diferencia máxima entre las variedades apenas superior al medio punto. Los encuestados otorgan la consideración más positiva a las locuciones de los canarios, seguida de la de los rioplatenses, los caribeños y los mexicanos. Los locutores chilenos se encuentran en la zona media, mientras que en la zona de menor valoración se encuentran los locutores andaluces y, por último, los andinos. Se repite, por tanto, la postergación de las variedades andina y andaluza en la consideración de los jóvenes centro-norteños, aunque teniendo en cuenta siempre que la consideración global de estas variedades es alta. 


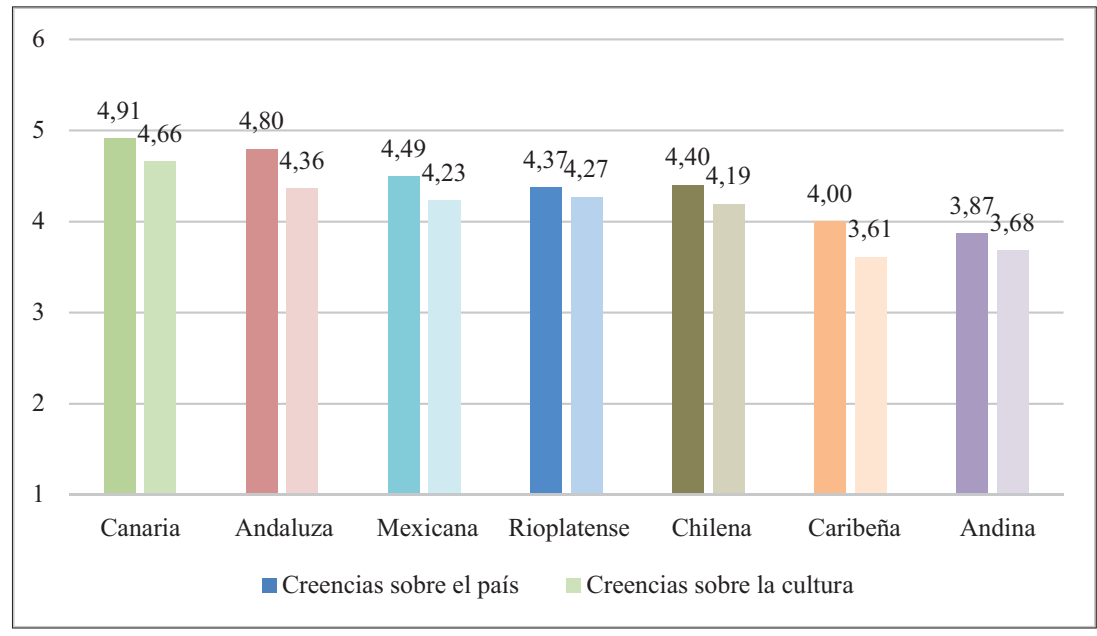

Gráfico 24. Creencias de los jóvenes universitarios del centro-norte peninsular sobre las características del país y de la cultura (valoración media)

Por último, en cuanto a las creencias de los jóvenes universitarios del centro-norte de España en relación con el país o región y su cultura, se constata de nuevo la alta consideración que se tiene sobre ambos aspectos. Tomadas en conjunto todas las variedades, la valoración es bastante positiva: la media general relativa al país o región es de 4,4, ligeramente superior a la media global de la cultura asociada a ese territorio, que es de 4,1; esta preeminencia de la valoración del país sobre la cultura correspondiente se repite en la evaluación de cada una de las variedades (gráfico 24). Por otra parte, aunque las diferencias interdialectales son cortas, hay que señalar que los dos dialectos españoles, el canario y el andaluz, son los que obtienen la puntuación más alta. Este hecho es en cierta medida esperable, pues pone de manifiesto que para los jóvenes universitarios del centro-norte peninsular, la valoración del propio país, España, y su cultura prevalece sobre cualquier otra zona hispanohablante. En cuanto a las variedades americanas, la mexicana y las del Cono Sur -rioplatense y chilena- alcanzan valoraciones más altas que las del Caribe y los Andes, que ocupan las posiciones más bajas en la puntuación. 


\section{CONCLUSIONES}

Los resultados que se han presentado coinciden en algunos puntos con los de estudios previos, basados en cuestionarios, como el de Moreno y Moreno (2004) o el de Yraola (2014), pero son comparables solo parcialmente. A diferencia de los anteriores, el proyecto PRECAVES XXI se basa exclusivamente en la técnica de los pares falsos (matched-guise), es decir, se sirve de audiciones reales de hablantes reales mediante las que se pretende evaluar la percepción de las variedades cultas del español. Esta es, sin duda, una de las principales aportaciones del proyecto y del trabajo que ahora se presenta y el principal valor de las conclusiones de este estudio.

En cuanto a la primera de las preguntas de investigación planteadas al comienzo de la investigación, que se refiere a las creencias acerca de la existencia de una variedad "mejor" o más prestigiosa, los datos ratifican que entre los jóvenes universitarios del centro-norte peninsular persiste el estereotipo de que no todos los territorios son equivalentes en su modo de hablar español. Por el contrario, la creencia mayoritaria es que existe un "mejor español" que, en términos generales, se identifica con el castellano de Castilla y con el habla de las ciudades. Esta creencia está más arraigada cuanto menor es el grado de formación recibida: entre los estudiantes de carreras no filológicas la creencia prácticamente es categórica, mientras que baja considerablemente a medida que aumenta el conocimiento y la formación dialectal. Los otros dos factores que influyen en esta creencia son la edad y el sexo y señala que los menores de 20 años y las mujeres tienden más a creer en la existencia de jerarquía entre las variedades del español.

Los jóvenes universitarios del centro y norte de la España tienen una autopercepción positiva de la variedad propia, lo que está en consonancia con el hecho de que la variedad castellana sea considerada modelo idiomático y con el hecho de que la gran mayoría de encuestados identifique correctamente la variedad castellana en las audiciones y se reconozca como usuario de ella. Las creencias y actitudes hacia la variedad castellana, considerada históricamente irradiadora de la norma lingüística general, son, sin duda, muy positivas, a juzgar por las valoraciones, directas e indirectas, que han hecho al contestar a las preguntas del cuestionario, especialmente las valoraciones indirectas de la variedad. Las valoraciones directas positivas, en cambio, son altas, pero no en exceso.

Por último, respecto a la pregunta acerca de en qué medida los sujetos del centro-norte de España identifican y valoran el resto de variedades cultas del español, hay varios aspectos que destacan. En primer lugar, el alto índice de reconocimiento e identificación exacta de variedades dialectales, índice 
que sube a medida que aumenta la formación del individuo en dialectología. No obstante, también hay que anotar que el grupo de quienes estudian para ser profesores de español como segunda lengua presentan unos porcentajes de identificación de dialectos algo bajos, si se tiene en cuenta el grado de especialización que deberían alcanzar en este sentido. Las variedades mejor identificadas por los sujetos son la rioplatense y la andaluza, especialmente por la acusada marcación de algunos de sus principales rasgos fónicos; la variedad que los encuestados han tenido más dificultades para identificar es la chilena. En segundo lugar, la valoración que se otorga a las variedades cultas es alto o muy alto, tanto en la valoración directa como en la indirecta. Entre los dialectos mejor valorados por los jóvenes centro-norteños de España se encuentran el rioplatense y el canario, mientras que los dialectos andaluz y andino se sitúan en el extremo contrario.

Los resultados que se acaban de ofrecer son parciales, pues corresponden sobre todo a un perfil muy específico de sujetos: el de quienes están más familiarizados con la diversidad dialectal del español y, por ello, son -o deberían ser- más conscientes de las repercusiones que pueden tener los estereotipos lingüísticos; las respuestas de estos encuestados del español centro-peninsular, no obstante, proporcionan datos básicos para avanzar de manera coordinada en el proyecto, ya que permitirán comparar las valoraciones obtenidas aquí con las valoraciones de ese mismo tipo de sujetos de los diferentes territorios hispanohablantes. Como se señala en el artículo introductorio de este volumen monográfico, se emplaza al lector a la siguiente fase del proyecto, que contará con una muestra representativa de todo el espectro social, para conocer la determinación explicativa de otros factores sociales (sexo, edad y nivel de instrucción) en la percepción de las variedades dialectales y las creencias y actitudes que generan.

\section{REFERENCIAS BIBLIOGRÁFICAS}

Almeida SuÁrez, Manuel. 1994. Creencias y actitudes en el español canario. Anuario de Lingüística Hispánica 10: 9-24.

Álvarez Rodríguez, Francisco y Ramón de Andrés Díaz. 2001. Una aproximación a las actitudes lingüísticas en Asturias. Textos de didáctica de la lengua y la literatura 26: 29-43.

Bentivoglio, Paola y Mercedes Sedano. 1999. Actitudes lingüísticas hacia las distintas variedades dialectales del español latinoamericano y peninsular. En Matthias Perl, Klaus Pörtl y Araceli Marín Presno (eds.). Identidad cultural y lingüística en Colombia, Venezuela y en el Caribe hispánico, pp. 135-160. Tübingen, Niemeyer.

Blas Arroyo, José Luis. 1995. De nuevo el español y el catalán, juntos y en contraste. Estudio de actitudes lingüísticas. Sintagma 7: 29-41. 
1999. Las actitudes hacia la variación intradialectal en la sociolingüística hispánica. Estudios Filológicos 34: 47-72.

Buzón García, José M., M. a Begoña Gómez Devís y José Ramón Gómez Molina. 2017. Actitudes lingüisticas en Valencia y su área metropolitana. Estudio longitudinal y análisis de tendencias. Valencia: Tirant Humanidades.

Casares Berg, Håkan, Xaquín Loredo Gutiérrez, Isabel Suárez Fernández, Xosé Antonio Fernández Salgado. 2003. Actitudes lingüísticas en Galicia. Grial: Revista Galega de Cultura 160: 52-59.

Casesnoves Ferrer, Raquel. 2001. Las actitudes lingüísticas de los jóvenes estudiantes de secundaria en la ciudad de Valencia. En Ana Isabel Moreno Fernández y Vera Colwell (eds.). Perspectivas recientes en el discurso. León: Universidad (publicación en CD).

Chiquito, Ana Beatriz y Miguel Ángel Quesada Pacheco (eds.). 2014. Actitudes lingüísticas de los hispanohablantes hacia el idioma español y sus variantes. Bergen: Universidad de Bergen (Colección: Bergen Language and Linguistics Studies (BeLLS), 5. Disponible en http://dx.doi.org/10.15845/bells.v5i0 [Consulta 07/2017].

Díaz-Campos, Manuel e Inmaculada Navarro-Galisteo. 2009. Perceptual Categorization of Dialect Variation in Spanish. Selected Proceedings of the $11^{\text {th }}$ Hispanic Linguistics Symposium, pp. 179-195. Somerville, MA: Cascadilla Proceedings Project.

Fernández Paz, Agustín. 2001. Las actitudes lingüísticas en situaciones de contacto de lenguas: el caso de Galicia. Textos de didáctica de la lengua y la literatura 26: 17-27.

García Mouton, Pilar y Francisco Moreno Fernández. 1987. Proyecto de un Atlas Lingüístico (y etnográfico) de Castilla-La Mancha (ALeCMan). En M. Ariza, A. Salvador y A. Viudas (eds.). Actas del I Congreso Internacional de Historia de la Lengua Española, pp. 14611480. Madrid: Arco/Libros.

Gómez Molina, José Ramón. 1998. Actitudes lingüísticas en una comunidad bilingüe y multilectal. Área metropolitana de Valencia. Cuadernos de Filología. Anexo XXVIII. València: Universitat de València.

2002. Lenguas en contacto y actitudes lingüísticas en la comunidad valenciana. En J. L. Blas et al. (eds). Estudios sobre lengua y sociedad, pp. 53-86. Castellón: Publicaciones de la Universidad Jaume I.

Hofseth, Birte. 2012. ¿Yo? ¡Yo hablo andaluz! Actitudes lingüísticas de los granadinos hacia su lengua materna. Tesina de Máster. Universidad de Bergen (Noruega).

Johansen-Toft, Janne Helen. 2007. Actitudes lingüísticas de los hablantes de Las Palmas de Gran Canaria hacia su propia habla. Tesina de Máster. Universidad de Bergen (Noruega).

Lambert, Wallace E., R. C. Hodgson, C. Gardner y S. Fillenbaum. 1960. Evaluative reactions to spoken language. Journal of Abnormal and Social Psychology 60: 44-51.

López Morales, Humberto. 2001. Actitudes lingüísticas hacia el bable en la ciudad de Oviedo. Lingüistica Española Actual XXIII/2: 145-157.

Martín Zorraquino, María Antonia. 1998. Sociolinguistic Attitudes and Beliefs Towards Dialectal and Standard Varieties in La Franja Oriental de Aragón (Spain). Folia Linguistica 32/1-2: 131-144.

Martínez González, Juan y José Luis Blas Arroyo. 2011. Estabilidad y dinamismo en las actitudes lingüísticas de una comunidad bilingüe española (Els Ports, Castellón). Hispania 94/4: 663-679.

Martínez, María y Juan Antonio Moya Corral. 2000. Reacciones actitudinales hacia la variación dialectal en hablantes granadinos. Lingüistica Española Actual XXII/2: 137-156.

Molina Martos, Isabel. 1998. La fonética de Toledo. Contexto geográfico y social. Alcalá de Henares: Servicio de Publicaciones de la Universidad de Alcalá. 
Moreno Fernández, Francisco y Juliana Moreno Fernández. 2004. Percepción de las variedades lingüísticas de español por parte de hablantes de Madrid. Lingüística Española Actual XXVI/1: 5-38.

Moreno Fernández, Francisco. 2009. La lengua española en su geografía. Madrid: Arco/ Libros.

Oroz Bretón, Nekane. 1988. Las actitudes hacia la lengua vasca en Navarra. Notas y estudios filológicos 13: 159-180.

Rojo SÁnchez, Guillermo. 1979. Aproximación a las actitudes lingüísticas del profesorado de E. G. B. en Galicia. Santiago: Universidad de Santiago de Compostela.

1981. Conductas y actitudes lingüísticas en Galicia. Revista Española de Lingüística 11/2: 269-310.

Siguán, Miguel. 1994. Conocimiento y uso de las lenguas de España. Madrid: Centro de Investigaciones Sociológicas.

VALLVERdú, Francesc. 1980. Aproximació crítica a la sociolingüistica catalana. Balanç dels estudis de sociologia lingüistica als Pä̈sos Catalans. Barcelona: Edicions 62.

Yraola, Aitor. 2014. Actitudes lingüísticas en España. En Ana Beatriz Chiquito y Miguel Ángel Quesada Pacheco (eds.). Actitudes lingüisticas de los hispanohablantes hacia el idioma español y sus variantes, pp. 551-636. Bergen: Universidad de Bergen (Colección: Bergen Language and Linguistics Studies (BeLLS), 5. Disponible en https://bells.uib.no/ index.php/bells/article/view/685 [Consulta 07/2017]. 